\title{
Sectoral Differentiation, Allocation of Talent, and Financial Development*
}

\author{
Esteban Jaimovich ${ }^{\dagger}$
}

July 2010

\begin{abstract}
I present a theory of development in which heterogeneously talented entrepreneurs require credit to start new projects and open new sectors. During development the variety of sectors expands, which allows better sorting of entrepreneurial talent. The paper shows that, in addition to increasing the average productivity of matches between agents and sectors, this process also mitigates informational frictions in the financial markets. Furthermore, the impact of sectoral variety on the operation of financial markets gives rise to an interesting feedback between financial development and R\&D effort, which may lead to different types of dynamics. A successful economy exhibits a progressive increase in the variety of sectors, which in turn enhances the operation of financial markets. However, a poverty trap may also arise. This situation is characterised by a rudimentary productive structure with poor matching of skills to activities and severely inefficient credit to talented entrepreneurs.
\end{abstract}

Key Words: Adverse Selection, Talent Allocation, Sectoral Diversification, Financial Development.

JEL Codes: D82, O12, O14, O16, O30.

\footnotetext{
*I am grateful to Andrew Newman and Nicola Pavoni for their advice, encouragement and very useful comments. I also thank Sami Berlinski, Maristella Botticini, Wendy Carlin, Thomas Gall, Maitreesh Ghatak, Jean Imbs, Carmen Marchiori, Vincenzo Merella, Imran Rasul, Thierry Verdier and Fabrizio Zilibotti for helpful comments, as well as several seminar participants. The usual disclaimer applies.

${ }^{\dagger}$ Collegio Carlo Alberto, Via Real Collegio 30, (10024) Moncalieri, Italy - esteban.jaimovich@carloalberto.org
} 


\section{Introduction}

Over the course of development, the variety of productive activities in the economy tends to increase in conjunction with the aggregate stock of capital and output. This observation implies that economic development manifests itself partly as a process of sectoral diversification and increasing specialisation within the economy, an idea that dates back to Adam Smith (1776) in his discussion of the division of labour and its relation with the size of the market (The Wealth of Nations, chapter 3). Such a dynamic pattern is also described by Allyn Young (1928, p. 537), who writes "industrial differentiation has been and remains the type of change characteristically associated with the growth of production." Similarly, Landes (1969, p. 5) argues that the most evident effects brought about by the Industrial Revolution were the gains in productivity and the increase in the variety of products and occupations.

I propose a theory in which this process of sectoral diversification helps to mitigate informational frictions affecting the operation of financial markets. Furthermore, the degree of sectoral variety is itself endogenous to the theory, and it is positively influenced by financial markets. As a result, sectoral differentiation and the operation of financial markets appear interrelated in the model, and this positive interaction becomes a key feature that shapes the patterns of development followed by different economies.

The paper studies the evolution of an economy populated by heterogeneously talented individuals. In particular, individuals are characterised by distinct intrinsic skills concerning different types of entrepreneurial activities. A key assumption is that these skills are private information. In such a context, when agents need credit to start up their projects, asymmetric information gives rise to an adverse selection problem linked to the allocation of skills and prevents the provision of efficient credit contracts to talented entrepreneurs.

The modelled economy is constituted by different productive sectors. Each of these sectors represents a particular industry or activity, and requires the application of some specific types of entrepreneurial skills. The appearance of new sectors is assumed to be the result of R\&D effort and innovations. This assumption reflects the idea that carrying out new productive activities requires first an increase in the stock of knowledge in the society.

The central point in this paper rests on the hypothesis that sectoral variety allows improvements in the self-selection of talents to sectors. This fact reduces the severity of the adverse selection problem in the credit market, enabling the provision of more satisfactory credit contracts to talented agents, which fosters their entrepreneurial investment. The impact of sectoral 
variety on the operation of credit market, in turn, gives rise to a positive feedback between financial development and innovation activities. Entrepreneurs are the agents who put innovations into practice in the economy. This means that the return to entrepreneurial investment is what ultimately determines the size of the market for innovations and the returns to R\&D effort. As a result, when talented entrepreneurs receive better credit contracts this also raises the incentives to undertake $R \& D$, while higher investment in $R \& D$ contributes to financial development (by expanding the variety of sectors and enabling better sorting).

Based on this setup, I present two main findings. First, there is a static efficiency result related to the degree of sectoral diversification: a larger variety of sectors helps to lessen the informational frictions in the credit market affecting talented entrepreneurs. In particular, given the heterogeneity of skills, sectoral variety allows better matching of agents to activities, which in turn raises the quality of the pool of credit applicants. In that regard, adverse selection here stems from an underlying problem of relative scarcity of sectors, because this hinders the efficient sorting of (unobservable) talents. When the variety of sectors is limited, a large number of agents have no other choice but to specialise in activities for which they might not be exceptionally talented. Asymmetric information concerning skills, in turn, spreads the negative consequences of low-productivity matches to other sectors in the economy, since it prevents the (ex-ante) screening of heterogeneous agents in the credit market. In other words, those agents who are not able to exploit their advantage inflict a negative externality (through the adverse selection problem) on those who, in principle, could exercise fully their intrinsic skills.

Second, from a dynamic perspective, the paper shows that some economies might follow successful development paths, while others might get trapped in an underdevelopment equilibrium. In the former case, development is characterised by a continuous process of sectoral differentiation. In addition, alongside development and expanding diversification, the allocation of talent improves and, concomitantly, the adverse selection problem preventing talented entrepreneurs from receiving efficient credit contracts is progressively mitigated. On the other hand, in the poverty trap, economies exhibit a rudimentary productive structure, with few active industries, and highly inefficient financial institutions. In that sense, the poverty trap is the result of a general organisational failure in the economy, leading to the collapse of several markets.

The idea that the efficiency of the credit market may be influenced and by agents' payoffs in other markets of the economy is already present in Ghatak, Morelli and Sjöström (2007). In particular, their model exploits an interesting general equilibrium feedback between the credit market and the labour market: when the economy is able to provide high wages, low-quality 
entrepreneurs find themselves better off selling their labour in the market. As a result, as a side effect, high wages help to "clean" the pool of credit applicants, reducing informational frictions and enabling better operation of the credit market which in turn helps sustaining high wages. ${ }^{1}$

Like Ghatak et al, I study the sorting of talents in a context of informational asymmetries. A new aspect of my model is that it integrates the ensuing credit market imperfection within a multi-sectoral endogenous growth model. Innovation and the expansion of the set of activities in the economy become thus key features of the model, since they allow an improved sorting of skills to sectors. Two new findings result from my model compared to Ghatak et al. First, it shows that innovation improves the assignment of skills, which in turn feeds back on innovation by increasing the returns to R\&D. Second, it highlights a new role for the innovation process, very different from the one traditionally stressed in the growth literature. Innovations are not only desirable because they directly augment the productivity of inputs, but also because they may help to mitigate frictions in financial markets. From that perspective, this paper is also contributing to the literature on sectoral variety and growth by proposing an additional channel whereby increased variety promotes development. ${ }^{2}$

Sectoral diversification as a factor leading to financial development is also studied by Acemoglu and Zilibotti (1997). They propose a growth model with technological indivisibilities where the degree of market incompleteness tends to disappear with capital accumulation, allowing better risk sharing of idiosyncratic shocks and, thus, further enhancing capital accumulation by risk-averse entrepreneurs. In my model, although financial development is aided by the level of sectoral diversification too, this is the result of a different mechanism: the alleviation of agency costs faced by talented entrepreneurs as the sorting of skills to activities improves when the variety of sectors expands. In a related contribution, Acemoglu and Zilibotti (1999) study the evolution of informational asymmetries and agents' performances over the development path.

\footnotetext{
${ }^{1}$ See also De Meza and Webb (2000) for another model where agents' outside options influence the efficiency of the credit market. Unlike Ghatak et al (2007), though, in their paper the value of agents' outside options are exogenously set.

${ }^{2}$ Sectoral differentiation has traditionally been considered to raise aggregate productivity by two distinct channels: 1) permitting the exploitation of economies of scale through increasing specialisation (e.g., Smith (1776), Young (1928), Romer (1990), Yang and Borland (1991), Jones (2008)); 2) enabling heterogeneously skilled agents to obtain a better match (e.g., Rosen (1978), Miller (1984), Kim (1989)). The contribution of this paper to that literature is then to show that sectoral differentiation brings about an additional positive effect on growth via improved sorting, because an increasing variety of activities helps to lessen the negative consequences of adverse selection linked to the allocation of skills.
} 
However, they focus on how a society manages to provide correct incentives to agents, and how incentives may become more effective as an economy grows. My paper instead studies how the assignment of heterogeneous skills evolves during development in a context of endogenous variety expansion.

Finally, the present paper is also closely related to the literature on financial market imperfections and poverty - e.g., Banerjee and Newman (1993), Galor and Zeira (1993), Piketty (1997), Aghion and Bolton (1997), Lloyds-Ellis and Bernhardt (2000), Mookherjee and Ray (2002), and Ghatak and Jiang (2002). These articles stress the influence of wealth distribution on the dynamic behaviour of the economy when agency costs lead to credit rationing. My paper contributes to this literature mainly through two different channels. It first provides an alternative micro-founded explanation (involving multiple sectors and multi-market interactions) of why agency costs in the credit market may arise in a developing economy. Secondly, it is able to generate dynamics whereby these agency costs are alleviated as an economy develops and sectoral diversification takes place.

Section 2 describes the basic setup of the model. Section 3 studies the static equilibrium of the economy; in particular it analyses the entrepreneurs' optimal choice in the presence of adverse selection. Section 4 introduces the innovation activities into the model, which endogenises the variety of sectors in the economy. Section 5 proceeds to the dynamic analysis of this economy. Section 6 discusses an important extension to the basic model. Section 7 presents and discusses some stylised facts consistent with the main predictions of the model. Section 8 concludes.

\section{Environment}

The paper considers a small economy enjoying full access to international financial markets. Life evolves over a discrete-time infinite horizon, $t=\{0,1, \ldots, \infty\}$. In each period $t$ a single-period lived continuum of agents with mass normalised to 1 is alive.

There exist in the economy a continuum of sectors indexed by the letter $i \in[0,1]$. Each sector $i$ represents a particular industry where a final good may be produced. The set of sectors $[0,1]$ is constant over time; however, not all sectors are necessarily active at any moment in time. In particular, at time $t$ only a fraction $n_{t}$ of all sectors are able to enjoy the activity of productive industries. Hereafter, $\mathcal{A}_{t} \subset[0,1]$ will denote the set of sectors with active industries at time $t$. The set $\mathcal{A}_{t}$ has Lesbegue measure $n_{t}$.

The availability of productive industries is assumed to be the result of innovations (either 
generated during the past or in the present). This reflects the idea that in order to produce a new type of good, it is first required to generate the knowledge needed to produce this new good. ${ }^{3}$ Once the activity that corresponds to sector $i$ is available, it never disappears (i.e., if sector $i \in \mathcal{A}_{t}$, then sector $i \in \mathcal{A}_{t+\delta} \forall \delta \geq 0$ ). To ease notation, henceforth I skip the use of time-subscripts when creating no confusion. Sectors belonging to $\mathcal{A}$ will be referred to as active sectors (and the remaining sectors will accordingly be called inactive sectors).

A sector $i \in \mathcal{A}$ provides the agents in the economy the chance to invest in an entrepreneurial project: Project- $i$. The return of Project- $i$ is random, subject to an idiosyncratic shock. Project$i$ 's return also depends on the application of some specific entrepreneurial skills, and on the amount of capital invested in the project. A full description of Project- $i$ is provided in the following subsection (equations (1) and (2) ahead in the text).

\section{$2.1 \quad$ Entrepreneurs}

At any time $t$, there exists a continuum of (prospective) entrepreneurs who are indexed by the letter $i \in[0,1]$. Henceforth, the entrepreneur $i$ will also be referred to as the type $i$.

The cohort- $t$ of entrepreneurs is alive during period $t$. A new cohort is born just at the end of the previous cohort's lifespan. Each (dying) entrepreneur procreates one (new) entrepreneur. For the moment, I assume agents are non-altruistic and are born with zero initial wealth (in Section 6 this assumption is relaxed). All entrepreneurs are risk-neutral, sharing identical preferences over consumption.

Entrepreneurs are heterogeneous with respect to their entrepreneurial skills. More precisely, if type $j \in[0,1]$ invests $k$ units of capital in Project- $i$, then his Project- $i$ 's gross return $\left(y_{i, j}\right)$ is given by:

$$
y_{i, j}=\theta_{i, j} f\left(k_{i, j}\right) .
$$

The function $f(k)$ is strictly increasing, strictly concave, twice continuously differentiable, and satisfies Inada conditions. The variable $k_{i, j}$ represents the amount of capital invested in Project- $i$ by type $j$. Capital fully depreciates during the process of production. Finally, $\theta_{i, j}$ denotes the realisation of a random variable with support $\{0,1\}$. The value taken by $\theta_{i, j}$ is drawn from the

\footnotetext{
${ }^{3}$ The concept of innovation should be understood here in a relatively broad sense. In particular, by innovation, I will either refer to the creation of a totally new activity (i.e., an invention), or to the generation of the additional knowledge that is required in order to bring and apply into the local economy technologies that are already available elsewhere. As it will become clear later on, what is crucial in our model is the fact that both types of innovation activities are costly in terms of local R\&D effort.
} 
following distribution function:

$$
\theta_{i, j}=\left\{\begin{array}{ccc}
1 & \text { with probability } & p_{i, j} \\
0 & \text { with probability } & 1-p_{i, j}
\end{array}\right.
$$

where,

$$
\begin{array}{ll}
p_{i, j}=1 & \text { for all } i, j \in[0,1] \text { if } j=i, \\
p_{i, j}=p \in(0,1) & \text { for all } i, j \in[0,1] \text { if } j \neq i .
\end{array}
$$

In short, type $i$ is an agent with intrinsic advantage in Project- $i{ }^{4}$ Gross returns of Project- $i$ are thus given by:

$$
\begin{aligned}
& y_{i, i}=f\left(k_{i, i}\right) \\
& y_{i, j}\left(\theta_{i, j}\right)=\left\{\begin{array}{ll}
f\left(k_{i, j}\right) & \text { with probability } p \\
0 & \text { with probability } 1-p
\end{array}, \text { where } j \neq i\right.
\end{aligned}
$$

Diversification among entrepreneurial projects is not feasible. In other words, agents must specialise in, at most, one particular project.

Concerning the informational structure in the economy, entrepreneurial types are assumed private information. Project outcomes, on the contrary, are publicly observable. In addition to that, I assume types are intergenerationally uncorrelated, implying that parents' historical outcomes provide no information whatsoever about the type of a child.

Lastly, I assume that everybody has access to a "backyard" activity which requires no initial investment and yields net return equal to $v$ with certainty. Without loss of generality, I set $v=0$ (implying that the corresponding participation constraint will never bind). ${ }^{5}$

\subsection{Innovations}

Before deciding in which activity to specialise, an entrepreneur may choose to undertake some (costly) $\mathrm{R} \& \mathrm{D}$ effort in order to turn a previously inactive sector into an active sector (i.e., an

\footnotetext{
${ }^{4}$ Strictly speaking, this is an absolute advantage. The model could actually assume a comparative advantage by each agent $i$ in each sector $i$ (for example, by assuming that $p_{i, i}>p_{i, j}$ for all $i$ and $i \neq j$, but with those probabilities differing across agents and with some agents displaying higher average success probabilities). This alternative setup would not alter the main insights of the paper. However, assuming an absolute advantage in one specific sector (and symmetric across agents) substantially simplifies the operation of the model.

${ }^{5}$ If $v>0$, agents would have access to an outside option with positive payoff, hence their participation constraint may bind in equilibrium. This might have some minor implications on the type of credit contracts observed in equilibrium, however, none of the main results and insights of the paper would be altered by letting $v>0$.
} 
entrepreneur alive in $t$ may try to generate the knowledge required to turn some sector $i \notin \mathcal{A}_{t-1}$ into an active sector in $t$ ). Whether or not an entrepreneur undertakes such R\&D effort (and how much of it) will be part of his optimisation problem. More precisely, the optimal level of $\mathrm{R} \& \mathrm{D}$ effort will be the result of comparing the returns he expects to get from having the chance to specialise in the newly created activity versus the costs involved by that. To simplify the exposition, the explicit introduction of innovation effort will be postponed until Section 4 .

\subsection{Credit Markets}

Since agents in the economy are born with zero wealth, they will need to rely on credit markets in order to undertake their investment projects. The rest of the world will provide local agents with the needed funds. All credit market transactions with the rest of the world are mediated by some firms called financial intermediaries. The local credit market is characterised by free-entry and absence of set-up or sunk costs. Since the economy is small and there is perfect international capital mobility, financial intermediaries are able to draw liquid funds from international credit markets facing a perfectly elastic supply at the international (net) interest rate $R^{f}$. In the sake of algebraic simplicity, let $R^{f}=0$.

Financiers will offer loan contracts stipulating the payment to be made to them, conditional on the outcome of the entrepreneurial project. Individuals in the economy are protected by limited liability. As a result, since in the event of failure projects yield zero output, entrepreneurs will be able to pay back a positive amount to the financiers only in the case of success. Equilibrium loan contracts will thus display the following structure: $\left(l_{j}, r_{j}\right) \in \mathbb{R}_{+} \times \mathbb{R}_{+}$, where $l_{j}$ represents the loan extended to type $j$ and $r_{j}$ stands for the (net) interest rate charged on $l_{j}$ in the event of success. In other words, the entrepreneur $j$ must pay back $l_{j}\left(1+r_{j}\right)$ in the state of success, while if the project fails he goes bankrupt and the financier recovers 0 income. ${ }^{6}$

\section{$3 \quad$ Static Equilibrium Analysis}

Throughout this section the set of active sectors $\mathcal{A}_{t}$ is taken as exogenously given. Thus, this section focuses on the optimal behaviour of the entrepreneurs, and on the set of credit contracts offered by the financial intermediaries, given $\mathcal{A}_{t}$. In the next sections I proceed to study the

\footnotetext{
${ }^{6}$ Nothing in the model would change if entrepreneurs raised capital by issuing equity, as each share will pay zero in the event of failure and a strictly positive dividend in the event of success that is identical for all entrepreneurial projects.
} 
dynamic evolution of the economy; this will require explicitly incorporating the innovation effort undertaken by the entrepreneurs into their optimal plans.

Let $\mathcal{C}_{t}$ denote the set of credit contracts offered by financial intermediaries in period $t$. An entrepreneur $j \in[0,1]$ alive during $t$ will choose an allocation $\left[\left(r_{j}, l_{j}\right)^{*}, k_{i, j}^{*}: i \in \mathcal{A}_{t}\right]$, solving the following two-stage optimisation problem:

- Specialisation-stage: $j \in[0,1]$ selects sector $i \in \mathcal{A}_{t}$ in which to invest.

- Investment-stage: ${ }^{7}$

$$
\begin{aligned}
\max _{k_{i, j},\left(r_{j}, l_{j}\right)}: E_{i}\left(U_{j}\right)=p_{i, j} \max & \left\{0, f\left(k_{i, j}\right)-\left(1+r_{j}\right) l_{j}+\left(l_{j}-k_{i, j}\right)\right\} \\
+ & \left(1-p_{i, j}\right) \max \left\{0,-\left(1+r_{j}\right) l_{j}+\left(l_{j}-k_{i, j}\right)\right\}
\end{aligned}
$$

subject to: $k_{i, j} \leq l_{j} \quad$ (budget constraint),

$k_{i, j} \geq 0 \quad$ (feasibility constraint),

$\left(r_{j}, l_{j}\right) \in \mathcal{C}_{t} \quad$ (set of offered credit contracts).

Given the set $\mathcal{A}_{t}$, in equilibrium, the entrepreneurial allocations $\left\{\left(r_{j}, l_{j}\right)^{*}, k_{i, j}^{*}: i \in \mathcal{A}_{t}\right\}_{j \in[0,1]}$ and the set of offered credit contracts $\mathcal{C}_{t}$ must satisfy the following two conditions:

1) Entrepreneurs' optimal allocation: Given the set $\mathcal{C}_{t}$, for all $j$ alive in period $t$, the allocation $\left\{\left(r_{j}, l_{j}\right)^{*}, k_{i, j}^{*}: i \in \mathcal{A}_{t}\right\}$ solves the two-stage optimisation problem (I).

2) Credit markets (competitive) equilibrium: (i) No credit contract belonging to $\mathcal{C}_{t}$ makes negative expected profits; and (ii) there exists no other feasible credit contract $\mathfrak{z}$, such that $\mathfrak{z} \notin$ $\mathcal{C}_{t}$, and which, if offered in addition to $\mathcal{C}_{t}$, would make positive expected profits.

\subsection{Credit Market Equilibrium Contracts}

Following the literature on adverse selection in financial markets (e.g., Rothschild and Stiglitz (1976), Wilson (1977), and Milde and Riley (1988)), one would reasonably expect two different kinds of equilibria to possibly arise in this model's credit market: 1) a pooling equilibrium, in which all types receive an identical credit contract; 2) a separating equilibrium, in which types receive distinctive contracts that induce self-revelation of their (unobservable) skills.

\footnotetext{
${ }^{7} E_{i}\left(U_{j}\right)$ denotes the expected utility of type $j$ when he invests in Project- $i$ (recall that the success probability $p_{i, j}$ depends on the match between the type and the sector).
} 
Lemma 1 Assume the set of inactive sectors at time $t$ is non-empty (i.e., $\left.\mathcal{A}_{t} \neq[0,1]\right)$. Take any sector $i \in \mathcal{A}_{t}$ and any sector $j \notin \mathcal{A}_{t}$. Then, there can never exist an equilibrium at $t$ in which type $i$ and type $j$ choose different credit contracts.

Lemma 1 means that there cannot exist a separating equilibrium in this model. As a consequence, if an equilibrium is to exist at all, it should entail pooling credit contracts. This result stems from the conjunction of four different assumptions: $i$ ) risk-neutrality, ii) the limitedliability constraint, iii) agents being born with zero initial wealth (so they can place no collateral), and $i v$ ) the fact that the outside option yields $v=0$. Intuitively, given a set of credit contracts, any contract that maximises net returns for (1) must also necessarily maximise expected net returns for (2) (since, in the presence of limited liability and no collateral, expected net returns when (2) holds are proportional to net returns when (1) prevails). ${ }^{8}$

Given the set of active sectors at time $t, \mathcal{A}_{t} \subset[0,1]$, we may split the population alive during $t$ in two disjoint subsets: the first subset composed by all those types- $i \in[0,1]$, such that sector $i \in \mathcal{A}_{t}$; the second one by all those types- $j \in[0,1]$, such that sector $j \notin \mathcal{A}_{t}$. The first group of agents would be able to exploit fully their intrinsic skills, whereas the second one have to specialise in a sector for which they are not (exceptionally) talented. Abusing a bit of the language utilised in the adverse selection literature, I will call the first group the good types, while the second group will be denoted as the bad types. ${ }^{9}$

In a pooling equilibrium, all entrepreneurs receive an identical credit contract $\mathcal{C}_{t}=(l, r)$. Additionally, in any (competitive) pooling equilibrium, credit contracts must necessarily verify the following two properties. First, the contract must make non-negative expected profits; otherwise this contract would simply be withdrawn. Second, the contract must maximise the expected utility of the good types; otherwise financiers could offer a different contract such that it makes non-negative profits and, at the same time, it makes these agents better off.

\footnotetext{
${ }^{8}$ See Ghatak, Morelli and Sjöström (2007), and also Grüner (2003), for models that obtain pooling contracts in a similar fashion. Pooling contracts are especially attractive in this context because they lead to a very neat and smooth characterisation of the main results of this paper. Yet, pooling contracts, and in particular the assumptions required for pooling to arise, are by no means crucial. What is essential here is the fact that as more sectors become active and the matching of skills improves, the informational frictions affecting the most talented entrepreneurs in the credit market are eased.

${ }^{9}$ More rigorously: good types $t=\left\{h \in[0,1] \mid\right.$ sector $\left.h \in \mathcal{A}_{t}\right\}$ and bad types $t_{t}=\left\{h \in[0,1] \mid\right.$ sector $\left.h \notin \mathcal{A}_{t}\right\}$. Notice that in this paper whether a particular Type- $h \in[0,1]$ is a good type or a bad type is not fixed, but it is contingent of the set $\mathcal{A}_{t}$. In that sense, from a dynamic point of view, everyone could eventually become a good type, if the set of active sectors constantly expands over time.
} 
Assume for the moment that type $i$ chooses to specialise in sector $i \in \mathcal{A}$ (as it will become clear later on, this will necessarily be true in equilibrium). Then, given $\mathcal{C}_{t}=(l, r)$, his optimisation problem boils down to:

$$
\begin{aligned}
\max _{k_{i, i} \geq 0} & : \quad \max \left\{0, f\left(k_{i, i}\right)-(1+r) l+\left(l-k_{i, i}\right)\right\} \\
\text { s.t } & : \quad k_{i, i} \leq l \quad \text { (budget constraint). }
\end{aligned}
$$

Note now that because $r \geq 0$ (otherwise financiers would make losses on entrepreneurial loans), entrepreneurs will borrow only with the intention to invest in a project. As a consequence, $k_{i, i}=l$ will hold in the optimum and Problem (I') will yield:

$$
f^{\prime}\left(k^{*}\right)=(1+r)
$$

From (3), we can then obtain the optimal amount of capital invested in the project, given the interest rate $r$. That is, $k^{*}(r)$; where $k^{\prime}(r)<0$ since $f^{\prime \prime}(\cdot)<0$. An equilibrium pooling contract will, therefore, display the following structure: $(l, r)=\left(k^{*}(r), r\right)$.

\subsection{The Equilibrium Interest Rate}

The pair $\left(k^{*}(r), r\right)$ characterises the equilibrium credit contract, given the interest rate $r$. Therefore, in order to determine the exact credit contract that holds in $t$, it still remains to find the equilibrium value of $r$ in $t$. Let us denote this variable by $r_{t}^{*}$.

Consider sector $i \in \mathcal{A}_{t}$ and suppose the type $i$ alive in $t$ decides to invest in Project- $i$. Then, given $r$, his consumption $\left(c_{i, i}\right)$ would be determined by:

$$
c_{i, i}=f\left(k^{*}(r)\right)-(1+r) k^{*}(r) .
$$

Now, suppose this type $i$ chooses to invest in Project- $x \in \mathcal{A}_{t}$, where $x \neq i$. In that case, his consumption $\left(c_{x, i}\right)$ would be given by $c_{x, i}=p\left[f\left(k^{*}(r)\right)-(1+r) k^{*}(r)\right]$. Since $c_{i, i}>c_{x, i}$, then, as long as sector $i \in \mathcal{A}_{t}$ this type $i$ will specialise in Project- $i$.

Consider now sector $j \notin \mathcal{A}_{t}$ and the type $j$ alive in period $t$. This agent could invest in any Project- $x$, such that sector $x \in \mathcal{A}_{t}$, obtaining as expected consumption:

$$
c_{x, j}=p\left[f\left(k^{*}(r)\right)-(1+r) k^{*}(r)\right]
$$

Since $p>0$ the equation (5) yields $c_{x, j}>0$, irrespective of the value taken by $r$. This implies that it will always be desirable for type $j$ to invest $k^{*}(r)$ in Project- $x$. 
From the previous discussion, it follows that a fraction $n_{t}$ of the population of entrepreneurs (the good types) will always pay back the financial intermediaries the agreed amount $(1+r) k^{*}(r)$. On the other hand, the remaining fraction $1-n_{t}$ (the bad types) will go bankrupt with probability $1-p$. Being protected by limited-liability, the bad types are expected to pay back financiers only the amount $p(1+r) k^{*}(r)$.

Perfect competition in the credit market naturally implies that financiers must make zero profits in equilibrium. The zero-profit condition on entrepreneurial loans is given by: $n_{t}(1+$ $\left.r_{t}^{*}\right) k^{*}\left(r_{t}^{*}\right)+\left(1-n_{t}\right) p\left(1+r_{t}^{*}\right) k^{*}\left(r_{t}^{*}\right)=\left(1+R^{f}\right) k^{*}\left(r_{t}^{*}\right)$.

Proposition 1 The equilibrium interest rate charged on credit contracts offered to entrepreneurs is a decreasing function of the fraction of active sectors. More precisely,

$$
r_{t}^{*}=r^{*}\left(n_{t}\right)=\frac{\left(1-n_{t}\right)(1-p)}{n_{t}+\left(1-n_{t}\right) p} .
$$

From (6), it can also be noted that: $r^{*}(0)=(1-p) / p, r^{*}(1)=0$, and $r^{\prime \prime}\left(n_{t}\right)>0$.

Proposition 1 represents one the key insights of the paper. A larger number of active sectors allows better sorting of entrepreneurial skills, which in turn implies that the severity of the adverse selection problem in the credit market, in terms of cross-subsidisation from good to bad types, is reduced. Intuitively, as the set $\mathcal{A}_{t}$ expands, a higher fraction of agents find it feasible to specialise in the sector they are most talented at. This lowers the average default rate in the economy, enabling financiers to charge a lower interest rate on the loans they extend to entrepreneurs, without incurring in expected losses. ${ }^{10}$

\subsection{Entrepreneurial Consumption Level / Net Returns}

Take again some type $i \in[0,1]$, such that sector $i \in \mathcal{A}$ (a good types representative). His consumption level will be dictated by (4). Denote such consumption level by $U_{g}(r)$. Then, differentiating (4) with respect to $r$, and taking (3) into account, we get:

$$
U_{g}^{\prime}(r)=-k^{*}(r)
$$

Select now some type $j \in[0,1]$, such that sector $j \notin \mathcal{A}$ (a bad types representative). His expected consumption will be given by (5). Hence, letting $U_{b}(r)$ denote the expected consumption level of a bad type, we obtain:

$$
U_{b}^{\prime}(r)=-p k^{*}(r)
$$

\footnotetext{
${ }^{10}$ Notice that $r^{*}$ represents also the risk premium in the economy. In that regard, it is the risk premium on entrepreneurial loans that diminishes as $n$ goes up due to the better sorting of talent.
} 
where derivation of (8) also makes use of (3).

Lemma 2 Let $\Delta(r) \equiv U_{g}(r)-U_{b}(r)$. Then, $\Delta(r)>0$ and $\Delta^{\prime}(r)<0$, for all possible values $r$ may take in equilibrium.

The proof of Lemma 2 is straightforward from inspection of (7) and (8). The derivative $\Delta^{\prime}(r)<0$ means that good types benefit from a fall in the interest rate $r$ more than bad types do. The reason for this result rests on the fact that good types never go bankrupt, thus they will appropriate the full reduction in debt cost induced by a lower $r$. On the other hand, since bad types go bankrupt with probability $(1-p)$, they will profit from a smaller $r$ only with probability $p<1$. Lemma 2 will play a key role in the computation of the optimal level of $\mathrm{R} \& \mathrm{D}$ effort.

\section{R\&D Effort, Innovations and Sectoral Variety}

I model the appearance of new active sectors as the result of innovations. I will focus only on horizontal innovations, as those are the kind of innovations that will lead to improvements in the allocation of agents' talents, which is the key mechanism at work in this theory.

At the beginning of each period $t$, before selecting their productive specialisation, each entrepreneur $i$ chooses how much R\&D effort to expend. Successful R\&D effort materialises in the creation of a new active sector. In other words, the effect of $R \& D$ effort is allowing the entrepreneur to operate in period $t$ in a sector $j \notin \mathcal{A}_{t-1}$. Technology is assumed to be a pure public good; that is, its use is non-rival and non-excludable. More precisely, once some particular entrepreneur $i$ decides to run a project in a newly created sector $j$, the underlying knowledge becomes readily (and instantly) available to all the other entrepreneurs from $t$ onwards. The level of R\&D effort is assumed to be unobservable to financiers. ${ }^{11}$

An innovation could be either interpreted as the invention of a completely new activity or, alternatively, as the generation of the knowledge required to adapt/apply foreign technologies in

\footnotetext{
${ }^{11}$ Even if R\&D effort were publicly observable, it is not straightforward that it could be used as a positive signal to financiers in this setup. In particular, two features of the model may play against the use of R\&D effort as such a signal. First, all entrepreneurs whose ideal sector is not active at birth are ex-ante identical, and they would play the same strategy in a Perfect Bayesian Equilibrium. Second, the set of entrepreneurs whose ideal sector is already active at birth is that for whom the incentives to undertake R\&D are actually lowest (since they do not need to open a new sector in order to find a perfect match). As a consequence, although the exact outcome will naturally depend on the off-equilibrium path beliefs, R\&D effort might actually signal financiers a higher likelihood to be a bad type rather than a good type.
} 
the local economy. In relation to this second interpretation, R\&D effort could also be thought of as the costs involved in designing the most appropriate goods (or technologies to produce those goods) for specific local markets. ${ }^{12}$

\subsection{Optimal R\&D Effort}

Entrepreneurs must expend effort in order to innovate. Effort generates disutility. Let $\iota_{i, t}$ denote the effort cost (measured in units of consumption) spent in R\&D activities by entrepreneur $i$ alive during period $t$. Additionally, denote by $\operatorname{Pr}\left(I_{i, t}=1\right)$ the probability that the there is an innovation in sector $i \notin \mathcal{A}_{t-1}$ during $t$.

Since entrepreneur $i$ has an intrinsic advantage in sector $i$, while he is equally (less) productive in all other sectors, then all the $\mathrm{R} \& \mathrm{D}$ effort by entrepreneur $i$ (i.e., $\iota_{i, t}$ ) is going to be directed towards sector $i$. In other words, it will never be optimal for entrepreneur $i$ to expend any effort in trying to innovate for a sector $j \neq i$. I assume $\mathrm{R} \& \mathrm{D}$ effort increases the chances to innovate; in particular (bearing in mind that all $\iota_{i, t}$ will be optimally directed towards sector $i$ ):

$$
\operatorname{Pr}\left(I_{i}=1\right)=\beta\left(\iota_{i}\right)
$$

where: $\beta^{\prime}(\iota)>0, \beta^{\prime \prime}(\iota)<0, \beta(0)=0, \lim _{\iota \rightarrow \infty} \beta(\iota) \leq 1$, and $\lim _{\iota \rightarrow 0} \beta^{\prime}(\iota)$ is finite. (The use of time subscripts on is skipped to ease notation.)

When sector $i \notin \mathcal{A}_{t-1}$, entrepreneur $i$ will choose the value of $\iota_{i}$ to maximise the expected return derived from having the chance to operate in sector $i$ in period $t$, net of its effort cost. This return is crucially linked to the gap in expected consumption between good and bad types, $\Delta\left(r^{*}\left(n_{t}\right)\right)$, since a successful innovation in sector $i \notin \mathcal{A}_{t-1}$ allows entrepreneur $i$ born in $t$ to find an activity for which he is most talented, rather than having to join a sector for which he is not especially talented. ${ }^{13}$

Let $\bar{\iota}_{t}$ denote the level of $\mathrm{R} \& \mathrm{D}$ effort by all the entrepreneurs belonging the subset $-\mathcal{A}_{t-1}^{-i}$, where $-\mathcal{A}_{t-1}^{-i}=\left\{j \in[0,1] \mid j \neq i\right.$ and sector $\left.j \notin \mathcal{A}_{t-1}\right\} .{ }^{14}$ When all innovations generated

\footnotetext{
${ }^{12}$ For example, we could think of type $i$ as an entrepreneur satisfying a specific (geographic) market in the economy. This entrepreneur could either choose to provide them with an already existing good, or actually trying to design the most appropriate good for this specific market. The former strategy may imply a cheaper alternative in terms of R\&D effort compared to the latter; however, it may also be expected to be less successful in terms of sales. (An implicit assumption here is that each entrepreneur has a knowledge advantage regarding local markets compared to the rest of the economy, which they may or may not choose to exploit.)

${ }^{13}$ If sector $i \in \mathcal{A}_{t-1}$, then the entrepreneur $i$ alive in $t$ trivially chooses $\iota_{i}=0$.

${ }^{14}$ This $\bar{\iota}_{t}$ should actually be a mapping $\bar{\iota}_{t}:-\mathcal{A}_{t}^{-i} \rightarrow[0, \infty)$, summarising the choice of $\iota$ by each entrepreneur
} 
during $t$ are actually put into practice (which will be true in equilibrium), we can observe that $n_{t}=n_{t-1}+\beta\left(\bar{\iota}_{t}\right)\left(1-n_{t-1}\right) \cdot{ }^{15}$ As a result, we may rewrite $\Delta\left(r^{*}\left(n_{t}\right)\right)=\Psi\left(n_{t-1}, \bar{\iota}_{t}\right)$. Lemma 3 characterises the optimisation problem concerning R\&D effort faced by entrepreneur $i$.

Lemma 3 Consider sector $i \notin \mathcal{A}_{t-1}$, and take the entrepreneur $i$ alive during $t$. He solves:

$$
\max _{\iota_{i} \geq 0}: \Pi_{i, t}\left(\iota_{i}, n_{t-1}, \bar{\iota}_{t}\right)=\beta\left(\iota_{i}\right) \cdot \Psi\left(n_{t-1}, \bar{\iota}_{t}\right)-\iota_{i}
$$

Where the function $\Psi\left(n_{t-1}, \bar{\iota}_{t}\right):[0,1] \times \mathbb{R}_{+} \rightarrow \mathbb{R}_{+}$is increasing in both of its arguments. More precisely: (i) $\Psi_{n}^{\prime}(\cdot)>0, \forall n_{t-1} \in[0,1]$ and $\bar{\iota}_{t} \geq 0$; and (ii.a) $\Psi_{\bar{\iota}}^{\prime}(\cdot)>0, \forall n_{t-1} \in[0,1$ ) and $\bar{\iota}_{t} \geq 0$, (ii.b) $\Psi_{\bar{\iota}}^{\prime}(\cdot)=0$ if $n_{t-1}=1$.

From Lemma 3 it immediately follows that $\Pi_{i, t}\left(\iota_{i}, n_{t-1}, \bar{\iota}_{t}\right)$ is increasing in both $n_{t-1}$ and $\bar{\iota}_{t}$. Intuitively, since active sectors never revert to inactive, the higher $n_{t-1}$ is, the higher $n_{t}$ is expected to be. As a result, relatively high values of $n_{t-1}$ will tend to be associated with relatively low levels of $r_{t}^{*}$ (Proposition 1). This, in turn, implies that the surplus generated by innovations, $\Delta\left(r_{t}^{*}\right)$, is expected to be large (Lemma 2). Similarly, larger values of $\bar{\iota}_{t}$ are also associated with higher $n_{t}$, leading thus to lower $r_{t}^{*}$ and higher $\Delta\left(r_{t}^{*}\right)$. In this case, the reason is that a larger $\bar{\iota}_{t}$ means more innovations will be generated, raising thus the value of $n_{t}$ (from a given $\left.n_{t-1}\right)$. In addition, note $\Psi_{\bar{l}}^{\prime}(\cdot)>0$ implies that there is a positive externality across R\&D effort by different entrepreneurs: this externality arises because when an entrepreneur produces an innovation, the value of $n_{t}$ goes up, which raises the return to innovation $\Delta\left(r_{t}^{*}\right)$ for all the other entrepreneurs who are considering to possibly expend positive R\&D effort.

Problem (II) leads to the following first-order condition:

$$
\beta^{\prime}\left(\iota_{i}^{*}\right) \cdot \Psi\left(n_{t-1}, \bar{\iota}_{t}\right) \leq 1 \quad \text { and } \quad \iota_{i}^{*}\left[\beta^{\prime}\left(\iota_{i}^{*}\right) \cdot \Psi\left(n_{t-1}, \bar{\iota}_{t}\right)-1\right]=0
$$

Proposition 2 Let $\iota_{i}^{*} \equiv \arg \max _{\iota_{i}}\left\{\Pi_{i, t}\left(\iota_{i}, n_{t-1}, \bar{\iota}_{t}\right)\right\}$. Then, $\iota_{i}^{*}=\iota_{i}^{*}\left(n_{t-1}, \bar{\iota}_{t}\right):[0,1] \times \mathbb{R}_{+} \rightarrow \mathbb{R}_{+}$, and it exhibits the following two properties: 1) $\iota_{i}^{*}\left(n_{t-1}, \bar{\iota}_{t}\right)$ is (weakly) increasing in $n_{t-1} ; 2$ ) $\iota_{i}^{*}\left(n_{t-1}, \bar{\iota}_{t}\right)$ is (weakly) increasing in $\bar{\iota}_{t}$.

Results in Proposition 2 are straightforward implications of Lemma 3 and equation (10). Intuitively, as $\partial \Pi_{i, t}(\cdot) / \partial \iota_{i}$ is increasing in both $n_{t-1}$ and $\bar{\iota}_{t}$, larger values of these variables will lead to a higher level of optimal R\&D effort.

belonging to $-\mathcal{A}_{t}^{-i}$. However, in the optimum, they all select the same value of $\iota$; hence, a singleton $\bar{\iota}_{t}$ turns out to be sufficient to represent their aggregate behaviour.

${ }^{15}$ This is because: 1$)$ the sectors that were already active in $t-1$ remain active in $t$, and 2$)$ a fraction $\beta\left(\bar{\iota}_{t}\right)$ among the inactive sectors in $t-1$ become active in $t$. 
The positive impact of $n_{t-1}$ on $\iota_{i}^{*}$ represents the key result of this section. This feature is the underlying force generating the positive feedback between financial development and innovation activities proposed here. Essentially, a larger $n_{t-1}$ is associated with weaker distortions in the credit market, thereby leading to higher entrepreneurial profit and, more importantly, higher talent premium. This induces higher R\&D effort which, in turn, leads to a faster rate of innovations, feeding back on $n_{t}$.

For the remainder of the paper, it proves convenient to restrict the parameters configuration such that the following two conditions hold:

Assumption 1. $\exists \bar{n} \in(0,1)$, such that: $\beta^{\prime}(0) \Psi(\bar{n}, 0)=1$.

Assumption 2. $\exists \underline{n} \in(0,1)$, such that: $\beta^{\prime}(0)\left[\lim _{\bar{\iota} \rightarrow \infty} \Psi(\underline{n}, \bar{\iota})\right]=1$.

Corollary 1 If Assumption 1 holds, then: (i) $\forall n_{t-1} \leq \bar{n}: \bar{\iota}_{t}=0 \Rightarrow \iota_{i}^{*}=0$; (ii) $\forall n_{t-1}>\bar{n}$ : $\iota_{i}^{*}>0$, regardless of the value taken by $\bar{\iota}_{t}$.

Corollary 2 If Assumption 2 holds, then: $\forall n_{t-1} \leq \underline{n}: \iota_{i}^{*}=0$, regardless of the value taken by $\bar{\iota}_{t}$. (Notice Lemma 3 implies $\underline{n}<\bar{n}$.)

Figure 1 illustrates the results stated in Proposition 2. The left panel plots $\iota_{i}^{*}$ against $n_{t-1}$, given four different values of $\bar{\iota}_{t}$ (these values are: $0<\bar{\iota}_{B}<\bar{\iota}_{A}<\infty$ ). Analogously, the right panel plots $\iota_{i}^{*}$ against $\bar{\iota}_{t}$, given five different values of $n_{t-1}\left(n_{A}<n_{B}<\bar{n}<n_{C}<1\right)$. Notice that the notation in both panels is consistent with each other (i.e., the value $\bar{\iota}_{A}$ in panel $(a)$ corresponds to the value $\bar{\iota}_{A}$ in panel $(b)$, and so on and so forth). Additionally, in Figure $1 . b$ (although not plotted) for $n_{t-1}=\underline{n}$ we should have $\iota_{i}^{*}\left(n_{t-1}, \bar{\iota}_{t}\right)=0$ for all values of $\bar{\iota}_{t}$.

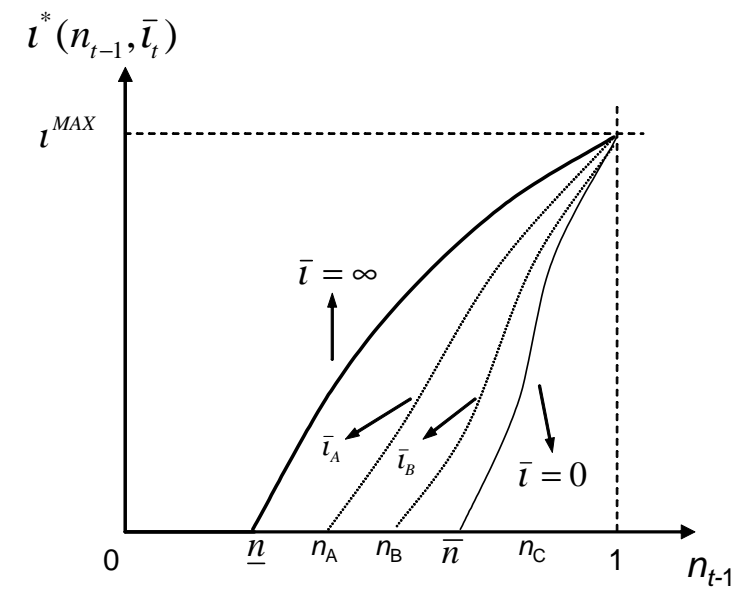

(a)

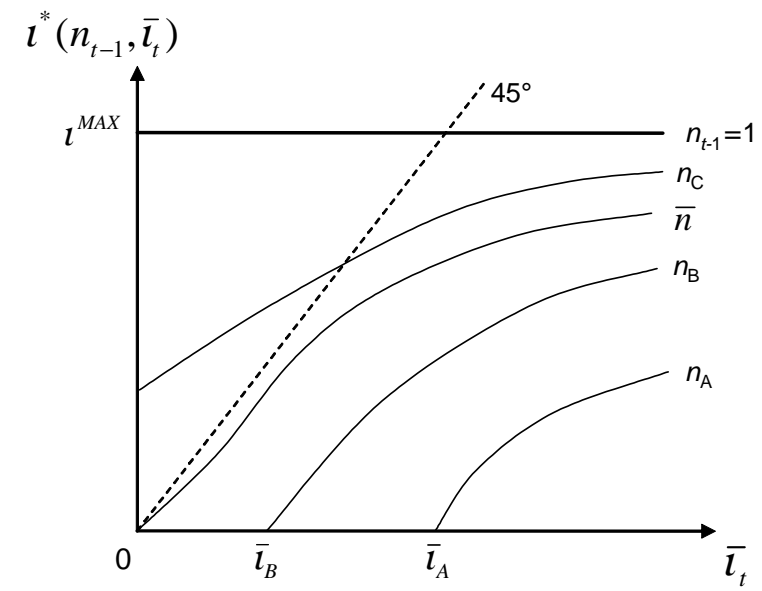

(b)

FiguRE 1: Optimal R\&D effort as a function of $n_{t-1}$ and $\bar{\iota}_{t}$. 


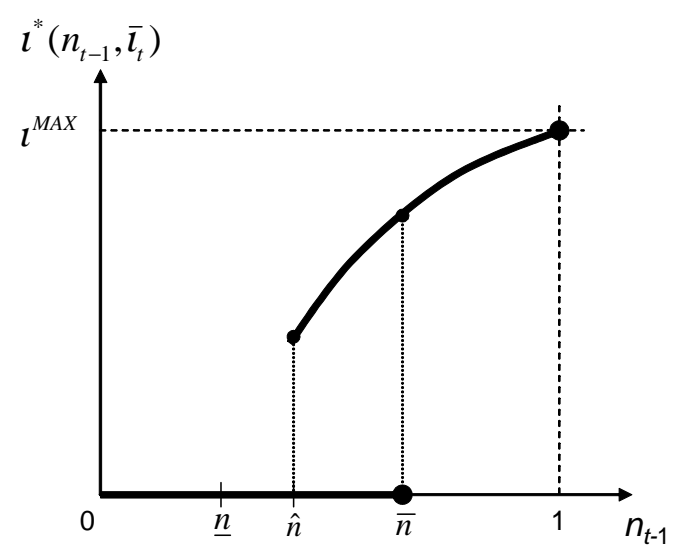

(a)

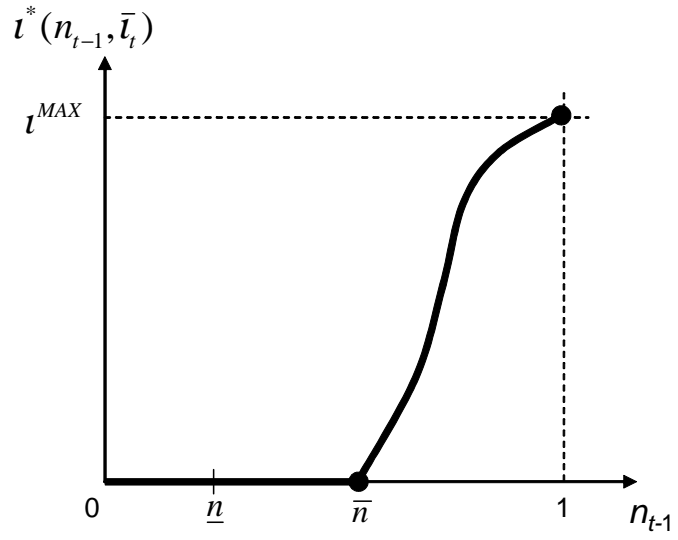

(b)

Figure 2: Nash Equilibrium in R\&D Effort.

\subsection{Nash Equilibrium Solution for R\&D Effort}

FIgURE 1 takes expectations about other entrepreneurs' behaviour as given. However, these expectations, summarised by $\bar{\iota}_{t}$, must be correct in equilibrium, and they play an important role because $R \& D$ effort by a particular entrepreneur exerts a positive externality on the others. More specifically, as stated in Proposition 2, the optimal R\&D policy of an entrepreneur positively depends on $\bar{\iota}_{t}$. As a result, we must restrict the attention only to solutions of Problem (II) which also represent a Nash Equilibrium (NE) when we consider all entrepreneurs together.

Given the structure of the model, any NE will be symmetric (SNE). The SNE are determined by the intersections between the $45^{\circ}$ line and the curves plotted in FigurE 1.b. For some ranges of $n_{t-1} \in(\underline{n}, 1)$, the model might lead to multiple SNE. ${ }^{16}$ Equilibrium multiplicity may arise because R\&D efforts are subject to strategic complementarity (Cooper and John (1988)). Figure 2 shows two possible SNE schedules as a function of $n_{t-1}$ (only the SNE schedule for entrepreneur $i$ alive in $t$ such that sector $i \notin \mathcal{A}_{t-1}$ is plotted). In FigurE 1.(b) and 2.(b) the parameters configuration leads always (i.e., for all values of $n_{t-1}$ ) to unique SNE. ${ }^{17}$ On the other hand, in Figure 2.(a) multiple equilibria emerge for values of $n_{t-1} \in(\widehat{n}, \bar{n})$. Two equilibria are possible in this case: one where $\iota_{t}^{*}=0$, and another one in which $\iota_{t}^{*}>0$. Bear in mind that, as it can be deduced from Corollary 2 , for any $n_{t-1} \leq \underline{n}$, the SNE must necessarily be unique and

\footnotetext{
${ }^{16}$ In what follows I restrict the analysis only to stable SNE.

${ }^{17} \mathrm{~A}$ sufficient condition for uniqueness of SNE is that: $\frac{\partial \iota^{*}}{\partial \bar{\iota}}=-\frac{\beta^{\prime}\left(\iota^{*}\right) \Psi_{\bar{\iota}}^{\prime}}{\beta^{\prime \prime}\left(\iota^{*}\right) \Psi(n, \bar{\iota})}<1, \forall n \in[0,1]$ and $\bar{\iota} \geq 0$. Generally speaking, uniqueness requires R\&D externalities not to be too strong, so that the curves plotted on Figure $1 . b$ never cross the $45^{\circ}$ line from below - see Cooper and John (1988).
} 
encompass $\iota_{t}^{*}=0$. Furthermore, for values of $n_{t-1}$ sufficiently close to 1 , the SNE must also necessarily be unique ( since $\lim _{n \rightarrow 1} \Psi_{\bar{\iota}}^{\prime}=0$ ); but comprising $\iota_{t}^{*}>0$ (because $0<\bar{n}<1$ ).

\subsection{A Short Digression about the Equilibrium under Full Information}

Suppose information about entrepreneurial skills were complete. In equilibrium, each type would be charged an interest rate that accurately reflects his intrinsic failure risk. In particular, good types would face a (net) interest rate equal to $R^{f}=0$ and thus would achieve $U_{g}^{F I} \equiv f\left(k^{*}(0)\right)-$ $k^{*}(0)$. On the other hand, bad types would face an interest equal to $r^{\max }=(1-p) / p$, obtaining $U_{b}^{F I} \equiv p f\left(k^{*}\left(r^{\max }\right)\right)-k^{*}\left(r^{\max }\right)$. Let $\Delta^{F I} \equiv\left(U_{g}^{F I}-U_{b}^{F I}\right)$, and notice that $\Delta^{F I}>\Delta(0)$, which is the maximum value that $\Delta(r)$ could possibly reach according to Lemma 2 . Therefore, the talent premium $\left(\Delta^{F I}\right)$ and the incentives to undertake $\mathrm{R} \& \mathrm{D}$ are largest when informational frictions preventing good types from receiving first-best credit contracts are absent. Moreover, notice that $\Delta^{F I}$ does not depend on the value of $n_{t}$ (in other words, it does not depend on the technology available in the economy at time $t$ ).

\section{$5 \quad$ Aggregate Dynamic Analysis}

The analysis in Section 3 has been conducted within a static framework (the set $\mathcal{A}_{t}$ was taken as given). Section 4 provides the bridge between the static and the dynamic analysis of the economy, by introducing the optimal R\&D effort choice. Here, I present the dynamics of $\mathcal{A}_{t}$. Since agents are born with zero initial wealth and all sectors are (ex-ante) symmetric, $n_{t}$ turns out to be the only variable whose behaviour we need to study in order to keep track of the dynamics of the economy.

Definition 1 (Dynamic Equilibrium) A dynamic equilibrium is a sequence of: REDD effort choices $\left\{\iota_{i, t}\right\}_{j \in[0,1]}$, entrepreneurial allocations $\left\{\left(r_{j}, l_{j}\right)^{*}, k_{i, j}^{*}: i \in \mathcal{A}_{t}\right\}_{j \in[0,1]}$, and offered credit contracts $\mathcal{C}_{t}$, linked together over time by the law of motion of $n_{t}$ specified in (11).

$$
\text { Law of Motion: } \quad n_{t}=n_{t-1}+\beta\left(\iota_{t}^{*}\right)\left(1-n_{t-1}\right)
$$

where $\iota_{t}^{*}$ denotes the RE्S effort by entrepreneur $h \in[0,1]$ alive in $t$ when sector $h \notin \mathcal{A}_{t-1}$, resulting from the SNE in Section 4.2. 


\subsection{Stagnation vs. Development (Multiple Dynamic Equilibria)}

This subsection investigates the characteristics of the dynamic paths followed by economies that differ in terms of their initial conditions. In particular, it studies whether economies may follow divergent dynamic paths, reaching different long-run equilibria. For this reason, I impose here the following condition on the parameters configuration (so that the SNE in R\&D effort will always be unique, leading to a situation as the one in Figure 2.b).

Assumption 3 (sufficient condition for uniqueness of SNE).

$$
\frac{\partial \iota^{*}}{\partial \bar{\iota}}=-\frac{\beta^{\prime}\left(\iota^{*}\right) \Psi_{\bar{\iota}}^{\prime}}{\beta^{\prime \prime}\left(\iota^{*}\right) \Psi(n, \bar{\iota})}<1 \text {, for all } n \in[0,1] \text { and } \bar{\iota} \geq 0 \text {. }
$$

Proposition 3 (Stagnation vs. Development) Suppose Assumptions 1 and 3 hold. Then:

(i) Any economy that starts off with $n_{0} \leq \bar{n}$ remains forever at $n_{0}$ and displays no innovation activities. That is, if $n_{0} \leq \bar{n}$, then: $n_{t}=n_{0}$ for all $t \geq 0$, while $\iota_{t}^{*}=0$ for all $t>0$.

(ii) In any economy in which $n_{0}>\bar{n}, n_{t}$ will continuously grow over time, converging monotonically to $n_{\infty}=1$.

Secular Stagnation: Take an economy for which $n_{0} \leq \bar{n}$. The equilibrium in $t=1$ encompasses $\iota_{1}^{*}=0$. In addition to zero R\&D effort and absence of innovations, this economy will exhibit highly inefficient credit contracts to talented entrepreneurs and low levels of entrepreneurial investment. From (11), since $\iota_{1}^{*}=0$, then $n_{1}=n_{0}$. This implies that $\iota_{2}^{*}=0$ will hold again at $t=2$, in turn leading to $n_{2}=n_{1}=n_{0}$. Furthermore, in the absence of any substantial exogenous shock, this stagnant equilibrium will perpetuate itself for all $t \in\{0,1, \ldots \infty\}$.

Prosperity and Development: Consider now an economy for which $n_{0}>\bar{n}$. In this case, the equilibrium at $t=1$ displays $\iota_{1}^{*}>0$. Intuitively, since $n$ is relatively large, the adverse selection problem faced by talented entrepreneurs does not become too serious, and the operation of the economy does not turn out to be so severely distorted (in particular, innovation activities do not fully disappear as the talent premium remains sufficiently high).

From (11), $\iota_{1}^{*}>0$ implies that some additional sectors become active during $t=1$. As a result, $n_{1}>n_{0}>\bar{n}$, and $\iota_{2}^{*}>\iota_{1}^{*}>0$. Moreover, this prosperous dynamics will perpetuate ad infinitum, and this economy will eventually reach a long-run equilibrium characterised by all sectors being active $\left(n_{\infty}=1\right)$. During the transition period, the economy experiences development and growth; this manifests itself as a process of progressive sectoral differentiation and better sorting of entrepreneurial skills. At the same time, financial market operation concomitantly improves, as adverse selection problems affecting the talent premium tend to vanish as $n_{t}$ rises. 


\subsection{History vs. Expectations (Multiple Static Equilibria)}

Section 4.2 has shown that, within the range of $n_{t-1} \in(\underline{n}, 1)$, for some set of parameters configurations the model might display multiple SNE in R\&D effort. As a particular example, in Figure 2. $a$, for $n_{t-1} \in[\hat{n}, \bar{n}]$, where $\hat{n} \in(\underline{n}, \bar{n})$, we find two possible (stable) SNE. This will lead to multiplicity of static equilibria in this model. It is beyond the scope of this paper to study this sort of equilibrium multiplicity, as the main intention here is to analyse how dynamic paths may depend on the initial conditions. Nevertheless, below I provide a brief discussion of the equilibrium characteristics of an economy whose parameters configuration leads to a situation as the one depicted in Figure 2. $a$.

In a situation like the one in Figure 2.a, then if the value of $n_{0} \in[\hat{n}, \bar{n}]$, this economy will be subject to multiple static equilibria. Equilibrium multiplicity will be driven by expectations. In particular, if expectations coordinate in $\bar{\iota}_{1}=0$, then $\iota_{1}^{*}=0$ will prevail. Besides this "bad" equilibrium, we can observe that there also exists some specific value $\bar{\iota}_{1}^{*}>0$, which would lead to a "better" equilibrium comprising $\iota_{1}^{*}=\iota_{1}^{*}>0$. More importantly, from a dynamic perspective, whether expectations in $t=1$ lead to $\iota_{1}^{*}=0$ or $\iota_{1}^{*}>0$ may carry dramatic future consequences. Dynamically, $\iota_{1}^{*}=0$ entails that $n_{t}$ stays stagnant during period $t=1$; as a result, initial conditions in $t=2$ would identically replicate those faced in $t=1$, with the economy still at risk of suffering from coordination failures. On the other hand, $\iota_{1}^{*}>0$ means that $n_{1}>n_{0}$ and, consequently, this could possibly shoot up $n_{1}$ above $\bar{n}$, and ignite a process of continuous prosperity and development thereafter. For an economy with $n_{t-1} \in[\hat{n}, \bar{n}]$, the larger $n_{t-1}$ is, the higher the chances that $n_{t}>\bar{n}$ will hold if $\iota_{t}^{*}>0$. Hence, within $[\hat{n}, \bar{n}]$, both history and expectations matter in the sense of Krugman (1991), and the economy might display periods of growth and technical change, followed by periods of stagnation.

\section{Incorporating Wealth into the Model}

So far it has been supposed that individuals are born with zero initial wealth. In many aspects this assumption might seem far too extreme. Nevertheless, the zero initial wealth assumption has allowed the model to fully isolate the impact of the fraction of active sectors on the operation of the economy.

In this section, I let agents be born with positive initial wealth; furthermore, I allow initial wealth to differ across individuals of the same cohort. Individuals are warm-glow altruistic and, accordingly, bequeath a fraction of their net life-time income to their offspring (this bequest will 
constitute the next generation's initial wealth). In short, this section shows that none of the main results and insights presented earlier are altered when we permit agents' initial wealth to be positive, stemming from parental bequests.

Let $w_{i, t}$ denote the initial wealth of the type $i$ alive in period $t$. Initial wealth is assumed publicly observable, and is distributed in the population of entrepreneurs according to the cumulative distribution function $\Omega_{t}(w)$. Since types are assumed to be intergenerationally uncorrelated, then, in a steady state, initial wealth and types will turn out to be uncorrelated as well (accordingly, the specific value of $w_{i, t}$ will provide no information about the $i$ 's type).

\subsection{The Participation Constraint}

When initial wealth is positive we need to take care of the participation constraint $(P C)$ in the credit market. In particular, when $w>0$ a bad type might prefer not to engage in any credit market transaction, and behave as if he were in complete autarky, since he may now invest a positive amount of capital $(k \leq w)$ in a project, without the need to borrow.

Suppose a bad type with initial wealth $w$ must choose his portfolio allocation in autarky. In such case, he will solve:

$$
\max _{0 \leq k \leq w}: p f(k)+(w-k) .
$$

This optimisation problem yields the following investment policies: $i$ ) $k^{*}=w$ if $w \leq k_{B}^{*}$, ii) $k^{*}=k_{B}^{*}$ if $w>k_{B}^{*}$. Where $f^{\prime}\left(k_{B}^{*}\right)=p^{-1}$ (i.e., $k_{B}^{*}$ is the bad types' first-best investment level).

Imagine now that this bad type decides to participate in the credit market. In this case, he will invest $k_{P}^{*}(r)$ units of capital in the project, paying an interest rate $r$ on the borrowed amount $\left(k_{P}^{*}(r)-w\right)$; where $r$ corresponds to the interest rate that would hold in a pooling equilibrium. The function $k_{P}^{*}(r)$ stems form the first-order condition $f^{\prime}\left(k_{P}^{*}\right)=1+r$; analogous to (3) in the main model. Notice that $1+r \leq p^{-1}$, hence $k_{P}^{*}(r) \geq k_{B}^{*}$.

A bad type will participate in the credit market only if his $P C$ is not violated; this requires that: $p\left[f\left(k_{P}^{*}(r)\right)-(1+r)\left(k_{P}^{*}(r)-w\right)\right] \geq p f\left(k_{B}^{*}\right)+\left(w-k_{B}^{*}\right)$, for $w>k_{B}^{*} \cdot{ }^{18}$ From this condition, it follows that a he will participate in the credit market if and only if his initial wealth does not surpass the threshold $\widehat{w}(r) \in\left(k_{B}^{*}, k_{P}^{*}(r)\right)$; that is, if and only if $w<\widehat{w}(r)$, where:

$$
\widehat{w}(r) \equiv \frac{p\left[f\left(k_{P}^{*}(r)\right)-f\left(k_{B}^{*}\right)-(1+r) k_{P}^{*}(r)\right]+k_{B}^{*}}{1-p(1+r)} .
$$

\footnotetext{
${ }^{18}$ The participation constraint also requires that: $p\left[f\left(k_{P}^{*}(r)\right)-(1+r)\left(k_{P}^{*}(r)-w\right)\right] \geq p f(w)$, for all $w \leq k_{B}^{*}$. Nevertheless, this last condition never binds.
} 


\subsection{The Incentive Compatibility Constraint}

Take now an entrepreneur whose $w \geq \widehat{w}(r)$. If he is a good type, he must get a separating credit contract (paying an interest rate equal to $R^{f}=0$ ), as no bad type with $w \geq \widehat{w}(r)$ desires to participate in the credit market at the (pooling) interest rate $r$. Despite that, a good type with $w \geq \widehat{w}(r)$ will not necessarily obtain a first-best credit contract. For this to happen, an equally rich bad type should find no incentives to imitate the good-type first-best behaviour. Denote with $k_{G}^{*}$ the result deriving from the first-order condition $f^{\prime}\left(k_{G}^{*}\right)=1$; i.e., $k_{G}^{*}$ designates the first-best investment level of the good types. Notice that $k_{G}^{*} \geq k_{P}^{*}(r)$, because $1+r \geq 1$. A good type will thus receive a first-best credit contract if and only if: $p\left[f\left(k_{G}^{*}\right)-\left(k_{G}^{*}-w\right)\right]<p f\left(k_{B}^{*}\right)+\left(w-k_{B}^{*}\right)$. This last condition requires that his initial wealth is larger than the threshold $\widetilde{w} \in\left(\widehat{w}(r), k_{G}^{*}\right)$; that is, it calls for $w>\widetilde{w}$, where:

$$
\widetilde{w} \equiv \frac{p\left[f\left(k_{G}^{*}\right)-f\left(k_{B}^{*}\right)-k_{G}^{*}\right]+k_{B}^{*}}{1-p} .
$$

What happens to a good type whose $w \in[\widehat{w}(r), \widetilde{w}]$ ? This agent will certainly receive a separating contract. However, he won't be able to get a first-best contract, as this would violate the incentive-compatibility constraint $(I C)$ of the bad types with identical $w$. In fact, the $I C$ will bind for those entrepreneurs whose $w \in[\widehat{w}(r), \widetilde{w}]$. As a result, the credit contract received by a good type with $w \in[\widehat{w}(r), \widetilde{w}]$ stems from the following condition:

$$
p\left[f\left(k_{S}^{*}\right)-\left(k_{S}^{*}-w\right)\right]=p f\left(k_{B}^{*}\right)+\left(w-k_{B}^{*}\right) .
$$

Equation (12) (implicitly) yields a function $k_{S}^{*}(w)$; which displays the following properties: $(i)$ $d k_{S}^{*} / d w=\frac{1-p}{p}\left(f^{\prime}\left(k_{S}^{*}\right)-1\right)^{-1}>0,(i i) d^{2} k_{S}^{*} /(d w)^{2}>0$, and $(i i i) \lim _{w \rightarrow \widetilde{w}} k_{S}^{*}(w)=k_{G}^{*}$.

TABLE 1 summarises the main features of the credit contracts offered to entrepreneurs. ${ }^{19}$

TABLE 1: Equilibrium Contracts (main features)

\begin{tabular}{|l|ccc|}
\hline & $w<\widehat{w}(r)$ & $w \in[\widehat{w}(r), \widetilde{w}]$ & $w>\widetilde{w}$ \\
\hline \hline type of credit contract & pooling & sub-optimal separating & first-best separating \\
investment by good types & $k_{P}^{*}(r)$ & $k_{S}^{*}(w)$ & $k_{G}^{*}$ \\
interest rate (on credit) & $0<r<\frac{1-p}{p}$ & 0 & 0 \\
\hline
\end{tabular}

\footnotetext{
${ }^{19}$ The underlying reason why richer agents receive more favourable credit contracts is the following: since richer agents have more of their own wealth at stake in the projects, their incentives are more closely aligned to those of lenders. A similar characterisation of the equilibrium entrepreneurial credit contracts at different wealth levels is present in Martin (2009), though in a static model.
} 


\subsection{Entrepreneurial Consumption and Sketch of Dynamics}

As in Section 3.3, denote by $U_{g}\left(U_{b}\right)$ the expected income level achieved by a good type (bad type). When initial wealth is incorporated into the model, it will naturally be the case that this will depend on $w$ as well - i.e., $U_{g}=U_{g}(r, w)$ and $U_{b}=U_{b}(r, w)$. TABLE 2 summarises how entrepreneurial expected income depends on $w$ (and $r$ ).

TABLE 2: Entrepreneurial Income $-U_{g}(r, w)$ and $U_{b}(r, w)$.

\begin{tabular}{|c|c|c|c|}
\hline & $w<\widehat{w}(r)$ & $w \in[\widehat{w}(r), \widetilde{w}]$ & $w>\widetilde{w}$ \\
\hline good types & $f\left(k_{P}^{*}(r)\right)-(1+r)\left(k_{P}^{*}(r)-w\right)$ & $f\left(k_{S}^{*}(w)\right)-\left(k_{S}^{*}(w)-w\right)$ & $f\left(k_{G}^{*}\right)-\left(k_{G}^{*}-w\right)$ \\
\hline bad types & $p\left[f\left(k_{P}^{*}(r)\right)-(1+r)\left(k_{P}^{*}(r)-w\right)\right]$ & $p f\left(k_{B}^{*}\right)+\left(w-k_{B}^{*}\right)$ & $p f\left(k_{B}^{*}\right)+\left(w-k_{B}^{*}\right)$ \\
\hline
\end{tabular}

From the results presented in TABLE 2, this lemma follows.

Lemma 4 Let $\Delta(r, w) \equiv U_{g}(r, w)-U_{b}(r, w)$. Then: (i) $\Delta(\cdot)>0, \forall w, r \geq 0$; (ii) $\Delta_{r}^{\prime}(\cdot)<0$, $\forall r \geq 0$ and $w \in[0, \widehat{w}(r)]$; (iii) a) $\Delta_{w}^{\prime}(\cdot)>0, \forall w \in[0, \widetilde{w})$ and $r \geq 0$; b) $\Delta_{w}^{\prime}(\cdot)=0, \forall w \geq \widetilde{w}$.

Lemma 4 represents the counterpart of Lemma 2, when entrepreneurs start their lives with positive wealth. On the one hand, Lemma 4 shows that Lemma 2's key result $\Delta_{r}^{\prime}(\cdot)<0$ holds as well when $0<w<\widehat{w}(r)$. On the other hand, it shows that the surplus $\Delta(\cdot)$ is (weakly) increasing in $w$, which implies that richer entrepreneurs benefit from a larger $n_{t}$ more than poorer entrepreneurs do. Furthermore, recall that the larger $\Delta(\cdot)$ is, the higher the incentives to R\&D (Lemma 3 and Proposition 2). Therefore, $\Delta_{w}^{\prime}(\cdot)>0$ entails that, for a given value of $n_{t}$-which, following Proposition 1, determines $r^{*}\left(n_{t}\right)-$, the aggregate distortions generated by the adverse selection problem in the credit market will become less severe the wealthier the economy is. FigURE 3 plots the surplus $\Delta(r, w)$ against $w$ at four different values of $r$ (namely: $\left.1 / p>r_{H}>r_{L}>0\right)$, to illustrate Lemma $4 .^{20}$

From a dynamic perspective, notice finally that economies exhibiting a larger $n_{t}$ tend to be richer as well. This is the case because the larger the fraction of active sectors, the higher the average productivity in the economy. As a result, introducing wealth dynamics into the model (by means of bequests, or any other reason that would still generate positive serial correlation in $w_{t}$ ) will not invalidate any of the main findings of this paper. In fact, as $n_{t}$ and wealth affect the

\footnotetext{
${ }^{20}$ Recall $r=p^{-1}$ when $n=0$, and $r=0$ when $n=1$. Additionally, notice $\widehat{w}^{\prime}(r)<0$, where $\lim _{r \rightarrow p^{-1}} \widehat{w}(r)=k_{B}^{*}$ and $\lim _{r \rightarrow 0} \widehat{w}(r)=\widetilde{w}$.
} 
economy's performance in the same direction, the presence of bequests will actually reinforce the dynamics previously discussed in Section 5 .

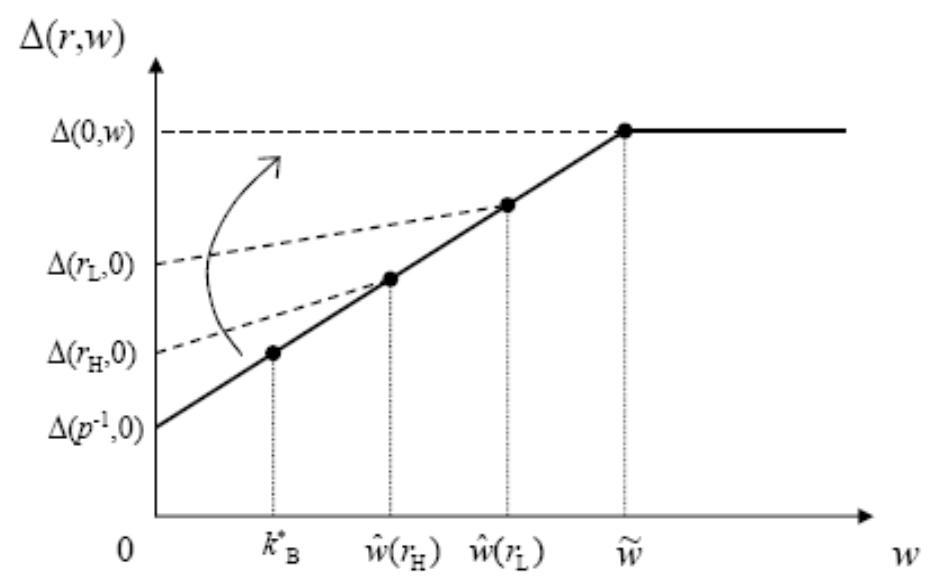

FiguRE 3: $\Delta(r, w)$ against $w$ at four different levels of $r$.

\subsection{Dynamics with Positive Bequests}

Suppose preferences over income are given by $U_{i, t}=c_{i, t}^{1-\delta} b_{i, t}^{\delta}$, where $c_{i, t}$ denotes the consumption of agent $i$ alive in $t, b_{i, t}$ represents the bequest left to his offspring, and $\delta \in(0,1)$. Given those preferences, individuals will optimally bequeath a fraction $\delta$ of their lifetime income to their offspring. The amount $b_{i, t}$ will in turn fully determine the initial wealth of $i$ 's son; i.e., $w_{i, t+1}=b_{i, t}$. Henceforth, we split the population of entrepreneurs in lineages indexed by the letter $i \in[0,1]$. Since types are intergenerationally uncorrelated, the initial wealth transition equations for any lineage $i$ of entrepreneurs are given by:

$$
\begin{aligned}
& w_{i, t+1}=\left\{\begin{array}{ll}
\delta\left[f\left(k_{P}^{*}\left(r_{t}\right)\right)-\left(1+r_{t}\right)\left(k_{P}^{*}\left(r_{t}\right)-w_{i, t}\right)\right] & \text { with } \operatorname{Pr}=n_{t}+p\left(1-n_{t}\right) \\
0 & \text { with } \operatorname{Pr}=(1-p)\left(1-n_{t}\right)
\end{array} \text { if } w_{i, t}<\widehat{w}\left(r_{t}\right)\right. \\
& w_{i, t+1}=\left\{\begin{array}{ll}
\delta\left[f\left(k_{S}^{*}\left(w_{i, t}\right)\right)-k_{S}^{*}\left(w_{i, t}\right)+w_{i, t}\right] & \text { with } \operatorname{Pr}=n_{t} \\
\delta\left[f\left(k_{B}^{*}\right)-k_{B}^{*}+w_{i, t}\right] & \text { with } \operatorname{Pr}=p\left(1-n_{t}\right) \\
\delta\left[w_{i, t}-k_{B}^{*}\right] & \text { with } \operatorname{Pr}=(1-p)\left(1-n_{t}\right)
\end{array} \quad \text { if } w_{i, t} \in\left[\widehat{w}\left(r_{t}\right), \widetilde{w}\right]\right. \\
& w_{i, t+1}= \begin{cases}\delta\left[f\left(k_{G}^{*}\right)-k_{G}^{*}+w_{i, t}\right] & \text { with } \operatorname{Pr}=n_{t} \\
\delta\left[f\left(k_{B}^{*}\right)-k_{B}^{*}+w_{i, t}\right] & \text { with } \operatorname{Pr}=p\left(1-n_{t}\right) \quad \text { if } w_{i, t}>\widetilde{w} \\
\delta\left[w_{i, t}-k_{B}^{*}\right] & \text { with } \operatorname{Pr}=(1-p)\left(1-n_{t}\right)\end{cases}
\end{aligned}
$$

When $w$ is linked across generations by bequests, the dynamics of the economy can no longer be solely determined by the value of $n_{t}$ but also depend on the initial wealth distribution $\Omega_{t}(w)$. 
In particular, the economy's dynamic path is now dictated by the following system:

$$
\begin{aligned}
n_{t} & =n_{t-1}+B_{t}^{*}\left(1-n_{t-1}\right) \\
\Omega_{t+1}(w) & =\Gamma_{t}\left[\Omega_{t}(w)\right] .
\end{aligned}
$$

Where:

$$
B_{t}^{*}=\int_{\Omega_{t}(w)} \beta\left(\iota^{*}\left(r_{t}, w\right)\right) d \Omega_{t}(w)
$$

and

$$
\iota^{*}\left(r_{t}, w\right)=\underset{\iota}{\arg \max }\left\{\beta(\iota) \Delta\left(r_{t}, w\right)-\iota\right\}
$$

Remark. Here we continue assuming that the NE of the R\&D effort game is always unique (or, alternatively, that coordination failures, never actually arise). Accordingly, from (15) and (16), abusing a bit of the notation, we could write $B_{t}^{*}=B_{t}^{*}\left(r_{t}\left(n_{t-1}\right), \Omega_{t}(w)\right)=B_{t}^{*}\left(n_{t-1}, \Omega_{t}(w)\right)$.

The operator $\Gamma_{t}[\cdot]$ maps the initial wealth distribution prevailing in period $t$ into the initial wealth distribution holding in $t+1$, based on the transition equations specified above. Notice that this operator changes over time, since the transition equations and their associated occurrence probabilities both depend on the value of $n_{t}$. Additionally, the dynamic behaviour of $n_{t}$ is affected by $\Omega_{t}(w)$ through (15). These two features of the dynamic system described by (13) and (14) make it non-stationary and highly complicated to study. However, the most important general results can be proven without much difficulty.

Lemma 5 (i) Consider two different initial wealth distributions $\Omega_{t}(w)$ and $\Omega_{t}^{\prime}(w)$, and suppose $\Omega_{t}(w)$ first-order stochastically dominates $\Omega_{t}^{\prime}(w)$ - henceforth denoted as $\Omega_{t}(w) \succeq \Omega_{t}^{\prime}(w)$. Then: $B_{t}^{*}\left(n_{t-1}, \Omega_{t}(w)\right) \geq B_{t}^{*}\left(n_{t-1}, \Omega_{t}^{\prime}(w)\right)$.

(ii) Consider two economies ( $A$ and $B$ ) with identical initial wealth distribution, i.e. $\Omega_{t}^{A}(w)=$ $\Omega_{t}^{B}(w)=\Omega_{t}(w)$. Suppose also that $n_{t}^{A}>n_{t}^{B}$. Then: $\Omega_{t+1}^{A}(w) \succeq \Omega_{t+1}^{B}(w)$.

Lemma $5(i)$ states that, all other things equal, wealthier economies tend to undertake more $\mathrm{R} \& \mathrm{D}$ and innovate more accordingly; its underlying intuition is straightforward from Lemma $4 .^{21}$ On the other hand, Lemma 5 ( $\left.i i\right)$ says that economies with a larger fraction of active sectors tend to be richer too. The reason for this result lies in two combined effects: first, a higher $n_{t}$ means that more agents are able to find a sector in which they have a comparative advantage,

\footnotetext{
${ }^{21}$ Notice that given the shape of $\Delta(r, w)$ as plotted in FigURE 3, we cannot say much about the effect of higher moments of $\Omega_{t}(w)$ on $\iota_{t}^{*}$. In particular, since $\Delta(r, w)$ has initially a convex segment (with respect to $w$ ), followed by a concave segment, the effect on $\iota_{t}^{*}$ of subjecting $\Omega_{t}(w)$ to a mean-preserving spread is ambiguous.
} 
increasing the average productivity in the economy; second, a higher $n_{t}$ leads to the provision of better credit contracts to the good types, spurring thus entrepreneurial investment. Lemma 5 thus formally proves that introducing wealth dynamics into the model (through bequests motives) reinforces the dynamics that have been described before in Section 5 .

Proposition 4 Suppose Assumption 1 holds, where we should now interpret $\Psi\left(n_{t-1}, \iota_{t}^{*}\right)=$ $\Delta\left(r_{t}^{*}\left(n_{t-1}, \iota_{t}^{*}\right), 0\right)$, and let $\Omega_{\widetilde{w}}\left(\Omega_{0}\right)$ denote the degenerate distribution function in which $w_{i}=\widetilde{w}$ $\left(w_{i}=0\right)$ for all $i \in[0,1]$. Then:

(i) If $n_{t-1}>\bar{n}, n_{t}$ will converge monotonically to $n_{\infty}=1$, regardless of $\Omega_{t}(w)$.

(ii) Suppose $\Omega_{t}(w)=\Omega_{\widetilde{w}}$. Then, there exists $\bar{n}_{\widetilde{w}}<\bar{n}$ such that if $n_{t-1}>\bar{n}_{\widetilde{w}}$, $n_{t}$ will converge monotonically to $n_{\infty}=1$

(iii) Suppose $\Omega_{0} \preceq \Omega_{t}(w) \preceq \Omega_{\widetilde{w}}$. Then, $\exists \bar{n}_{\Omega(w)} \in\left[\bar{n}_{\widetilde{w}}, \bar{n}\right]$ such that if $n_{t-1}>\bar{n}_{\Omega(w)}$, $n_{t}$ will converge monotonically to $n_{\infty}=1$. Furthermore, consider $\Omega_{t}(w) \succeq \Omega_{t}^{\prime}(w)$, then $\bar{n}_{\Omega(w)} \leq \bar{n}_{\Omega^{\prime}(w)}$.

Proposition 4 firstly shows that the main result in Proposition 3 still holds true when we incorporate standard wealth dynamics into the model - when $n_{t}$ is sufficiently large, the economy embarks in a process of long-run development, regardless of the wealth distribution in $t$. Secondly, it shows that initial wealth acts as a partial substitute for $n_{t}$. This last result stems from the fact that both $n_{t}$ and $w_{t}$ contribute to alleviate adverse selection problems in the credit market. Notice that Proposition 4 (ii) and ( $i i i)$ imply that the minimum degree of sectoral variety needed to guarantee long-run growth turns out to be smaller the richer the economy is. This result can be interpreted as saying that the importance of sectoral diversification as a factor improving the operation of financial markets is relatively higher at initial stages of development, and tends to decrease as the economy develops and becomes wealthier.

\section{Further Discussion: Some Stylised Facts in the Data}

This section briefly reviews some stylised patterns regarding the degree of sectoral diversification, financial development and entrepreneurial risk at different stages of development, consistent with the main predictions of the model.

\subsection{Sectoral Diversification and Development}

The model predicts that the variety of sectors expands as economies grow and develop. Using a panel of 67 countries, Imbs and Wacziarg (2003) find that sectoral concentration drastically 
falls at early stages of development, following a U-shape relationship with respect to income per head. In particular, the authors conclude is that, along the development path, economies initially experience a long process of sectoral diversification, which eventually reaches a maximum beyond where the process begins to revert.

Given the implications of my model, two observations concerning Imbs-Wacziarg's findings are worth stressing here: first, the turning point in the diversification process tends to occur at relatively high levels of income per capita (the authors argue that this point is located roughly at the income per head of Ireland in 1992); second, the eventual re-concentration process only partially offsets the effect of the initial diversification phase.

The Non-monotonic Diversification Path: The non-monotonic relationship found by Imbs and Wacziarg (2003) is also in itself an interesting result to somehow relate to the model. Although, strictly speaking, this paper does not lead to U-shaped dynamics, the results in Section 6 can yet shed some light on an interesting avenue for future research to contribute to explain such non-monotonicity. That section has shown that sectoral variety is most relevant to alleviate informational frictions at early stages of development. Then, as the economy grows and accumulates wealth, the use of collateral can actually substitute for the improved self-selection of skills allowed by sectoral variety. As a consequence, one may well expect that if there also exist gains from regional specialisation (such as increasing returns to scale), at some point in the development path, economies might find it worthwhile to sacrifice some degree of sectoral variety in order to better exploit increasing returns to scale.

\subsection{Financial Development, Growth and Diversification}

Starting with the seminal work by Goldsmith (1969) a large body of empirical literature has systematically documented a positive association between the level of financial development and economic growth. In particular, several cross-country studies have argued for positive causal effect from different measures of financial deepening on economic growth and capital accumulation; e.g., King and Levine (1993a, 1993b), Roubini and Sala-i-Martin (1992), Rajan and Zingales (1998), Levine and Zervos (1998). Moreover, the evidence seems to suggest that the efficiency of financial markets is especially critical to the profitability of firms subject to more severe asymmetric information problems (see discussion in Levine (1997), page 715).

The above literature is in general silent as to what actually determines the level of financial development of a specific economy. This paper suggests that this is crucially related to the 
degree of productive diversification via the improved matching of skills to activities it allows. Given that diversification is itself endogenous to the process of development, finding a causal effect requires the use of some source of exogenous variation for sectoral variety. In that regard, Ramcharan (2010) shows a positive and significant effect of sectoral diversification on financial deepening, using countries' topographical characteristics to instrument for diversification. ${ }^{22}$

Naturally, this last piece of evidence would also be also consistent with other explanations for why diversification helps financial development: for example, those suggested by Acemoglu and Zilibotti (1997), Saint-Paul (1992) or Greenwood and Jovanovic (1990). One specific result of my model, not present in those, is that also the returns to innovation rise with the degree of diversification, hence sectoral variety should spur innovation activities and technical change. Consistent with this last prediction, Feldman and Audretsch (1999) find that innovation activities tend to be lower in US cities that display a larger degree of industry specialisation. ${ }^{23}$

\subsection{Allocation of Talent, Growth and Firm-Level Volatility}

The model predicts that, as the variety of activities expands, thereby improving the quality of matches between entrepreneurial skills and activities, entrepreneurial risk and output volatility at the firm level should decline. ${ }^{24}$ Evidence of secular decline in firm-level volatility is presented by Davis et al (2006) who study the evolution of output growth variability of privately held firms in US during years 1976-2001. Relatedly, Koren and Tenreyro (2008) present evidence linking productivity of firms and their output variability, showing that as firms become more productive they also become less volatile. ${ }^{25}$

\footnotetext{
${ }^{22}$ The author uses the Gini coefficients of the distribution of land area by elevation and by bioclimatic classes to measure the degree of topographic variety of economies, and then uses these measures to instrument the degree of productive diversification.

${ }^{23}$ There exists also some evidence that relates the degree of productive diversification and innovation intensity at the firm level: e.g., Grabowski (1968), Scherer (1984), Garcia-Vega (2006). They tend to find a positive correlation between productive diversification within the firm and innovation intensity by the firm.

${ }^{24}$ This prediction differs from that delivered by Acemoglu and Zilibotti (1997), where firm-level volatility actually rises as sectoral variety expands over the process of development, since improved insurance against idiosyncratic risks enabled by sectoral diversification induces entrepreneurs to invest in riskier activities. On the other hand, Acemoglu-Zilibotti predicts that aggregate volatility in the economy should fall with development, while my paper cannot deliver this result due to the assumed continuum of agents which, by construction, averages out idiosyncratic shocks.

${ }^{25}$ Koren and Tenreyro (2008) also propose a theoretical model to explain the decline in firm-level volatility along development. Their model relies on the idea that, as firms grow they increase the variety of inputs they
} 
The model presented here also suggests that firm-level volatility and financial development should be negatively correlated. A recent paper by Correa and Suarez (2009) ties the decline in firm-level volatility to the operation of financial markets. They show that, following an increase in banking operation in some US states due to changes in their regulations, the types of firms that experience the largest fall in output variability are those which tend to rely more strongly on external funding.

\section{Concluding Remarks}

This paper has proposed a theory in which the efficiency of financial markets is a key condition for growth and development. I have suggested that an expanding variety of sectors may be an important factor leading to financial development. In particular, this theory has stressed a side effect associated with the innovation process that had not been explored before, but which could exert a significant impact on development. Innovation activities can lead to a reduction of frictions in the financial markets and foster financial development, because by expanding the variety of productive activities, they concomitantly facilitate the allocation of skills, and thereby alleviate adverse selection problems faced by talented entrepreneurs.

The core model that illustrates this theory has made use of several simplifying assumptions. An assumption that may seem particularly worrying is the fact that individuals are born with no initial wealth. In that regard, Section 6 has shown that none of the model's main findings are affected if we let agents be born with positive wealth. Despite not altering its main results, introducing wealth may carry some interesting additional implications within a more general model. Imagine that we gave room for increasing returns to scale and international trade. If sectoral diversification really matters as a mechanism to solve adverse selection only at early stages of development (as suggested by Section 6), then in the presence of increasing returns, at some point in the development path, economies might find it worthwhile to reverse the diversification tendency and start re-specialising in some specific sectors. This argument, which would be consistent with the evidence found by Imbs and Wacziarg (2003) of a U-shape relationship between sectoral diversification and income per head, is left open for future research.

Another feature that deserves further discussion is the behaviour of financial intermediaries. In the model, financiers respond "passively" to the environment. However, it can be argued that utilise (they call this process technological diversification), which by the law of large numbers helps to mitigate the effect of input-specific shocks on firms output. 
the operation of the financial system improves during development not only because frictions are alleviated, but also because the screening capacity of the financiers gets better. The paper has abstracted from the latter aspect. One remark concerning this omission is worth noting, though. The amount of screening effort is itself an endogenous choice, and it will certainly be influenced by the cost of screening. This paper states that screening effort is eased by sectoral variety, as this allows heterogeneous agents to self-select better. However, this does not necessarily imply that richer economies should conduct less credit screening than poorer ones. In fact, as sectoral variety decreases the cost of screening, in some cases, more screening effort could be the optimal response by lenders to the new environment, rather than simply denying credit so as to avoid the screening cost fully.

From a policy perspective, an important implication concerns poverty-alleviation programmes. Section 5 has shown that some economies might get stuck in a peculiar type of poverty trap. This is the result of a "deep-rooted" organisational failure, affecting several markets at the same time. Underdevelopment is characterised by few sectors in which individuals can specialise, inefficient financial markets, and scant innovation effort. The market failure contaminating the operation of the economy stems from the incapacity of some individuals to find an activity for which they are comparatively talented. Most theories on poverty traps imply that economies can be easily rescued from poverty by receiving a sufficiently large wealth transfer. In contrast, my theory suggests that poverty-alleviation policies should also aim at facilitating the matching of skills and technologies, as standard wealth transfers alone might not suffice to suppress the adverse selection problem (at least in a reasonably short time frame). 


\section{Appendix: Proofs}

Proof of Lemma 1. Take two different credit contracts $\left(l^{*}, r^{*}\right) \in \mathbb{R}_{+} \times \mathbb{R}_{+}$and $(\tilde{l}, \tilde{r}) \in \mathbb{R}_{+} \times \mathbb{R}_{+}$, such that $f^{\prime}\left(k=l^{*}\right) \geq 1$ and $f^{\prime}(k=\tilde{l}) \geq 1 .{ }^{26}$ Hence, in equilibrium, all the amount that is borrowed will be invested in the entrepreneurial projects. Accordingly, let's denote: $k^{*}=l^{*}$ and $\tilde{k}=\tilde{l}$. Assume that:

$$
f\left(k^{*}\right)-\left(1+r^{*}\right) k^{*}>f(\tilde{k})-(1+\tilde{r}) \tilde{k}
$$

Then, from (17), if type $i$ decides to specialise in sector $i \in \mathcal{A}$, he will prefer contract $\left(k^{*}, r^{*}\right)$ to contract $(\tilde{k}, \tilde{r})$.

Take now type $j$. Since sector $j \notin \mathcal{A}$, he will specialise (indifferently) in any sector $h \in[0,1]$, such that sector $h \in \mathcal{A}$. Given limited liability, type $j$ will (weakly) prefer contract $(\tilde{k}, \tilde{r})$ to contract $\left(k^{*}, r^{*}\right)$, if and only if:

$$
p[f(\tilde{k})-(1+\tilde{r}) \tilde{k}] \geq p\left[f\left(k^{*}\right)-\left(1+r^{*}\right) k^{*}\right]
$$

But, since $p>0$, (18) contradicts (17). Hence, it cannot be true that, while type $i$ prefers contract $\left(k^{*}, r^{*}\right)$ to contract $(\tilde{k}, \tilde{r})$, type $j$ prefers $(\tilde{k}, \tilde{r})$ to $\left(k^{*}, r^{*}\right)$ instead.

Proof of Proposition 1. The expression in (6) follows from the previous discussion in Section 3.2. Then, differentiating (6) with respect to $n_{t}: d r_{t}^{*} / d n_{t}=-(1-p)\left[n_{t}+\left(1-n_{t}\right) p\right]^{-2}<0$.

Proof of Lemma 3. Assume that the entrepreneur $i$ alive in $t$ expends $\iota_{i}$ units of effort. If he manages to generate an innovation, then from Lemma 2 it follows that his expected consumption will rise by $\Delta\left(r_{t}^{*}\right)$. Making use of Proposition 1 , we can write $\Delta\left(r_{t}^{*}\right)=\Delta\left(r^{*}\left(n_{t}\right)\right) \equiv \widetilde{\Delta}\left(n_{t}\right)$, where $\widetilde{\Delta}^{\prime}\left(n_{t}\right)=\Delta^{\prime}(\cdot) \frac{d r_{t}^{*}}{d n_{t}}>0$ (from Proposition 1 and Lemma 2). How is the value $n_{t}$ determined? Suppose all entrepreneurs belonging to $-\mathcal{A}_{t-1}^{-i}$ choose $\bar{\iota}_{t}$. Since active sectors in $t-1$ never revert to inactive in $t$, and recalling (9), then:

$$
n_{t}=n_{t-1}+\left(1-n_{t-1}\right) \beta\left(\bar{\iota}_{t}\right) \equiv \Phi\left(n_{t-1}, \bar{\iota}_{t}\right)
$$

Notice that, because $\beta\left(\bar{\iota}_{t}\right)$ is bounded away from 1, (19) implies $\Phi(\cdot)$ is increasing in both $n_{t-1}$ and $\bar{\iota}_{t}$. Now, plugging $\Phi(\cdot)$ from (19) into $\widetilde{\Delta}\left(n_{t}\right)$, we can rewrite $\widetilde{\Delta}\left(\Phi\left(n_{t-1}, \bar{\iota}_{t}\right)\right) \equiv \Psi\left(n_{t-1}, \bar{\iota}_{t}\right)$. From where it follows that: $(i) \Psi_{n}^{\prime}=\widetilde{\Delta}^{\prime}\left(n_{t}\right)\left(1-\beta\left(\bar{\iota}_{t}\right)\right) n_{t-1}>0 ;(i i) \Psi_{\bar{\iota}}^{\prime}=\widetilde{\Delta}^{\prime}\left(n_{t}\right)\left(1-n_{t-1}\right) \beta^{\prime}\left(\bar{\iota}_{t}\right)$, which leads to $\Psi_{\bar{\iota}}^{\prime}>0$ if $n_{t-1} \in[0,1)$ and $\Psi_{\bar{\iota}}^{\prime}=0$ if $n_{t-1}=1$. Finally, since entrepreneur $i$

\footnotetext{
${ }^{26}$ It must be straightforward to notice that entrepreneurs only borrow in order to finance entrepreneurial investment. Therefore, in equilibrium, they would never borrow beyond the point $f^{\prime}(k)=1$.
} 
will succeed in innovating for sector $i$ with probability $\beta\left(\iota_{i}\right)$, we may write: $\Pi_{i, t}\left(\iota_{i}, n_{t-1}, \bar{\iota}_{t}\right)=$ $\beta\left(\iota_{i}\right) \cdot \Psi\left(n_{t-1}, \bar{\iota}_{t}\right)-\iota_{i} ;$ which is the expression in Lemma 3.

Proof of Proposition 2. Part 1). Consider two values of $n_{t-1} ; n_{0}, n_{1} \in[0,1]$, such that $n_{0}<n_{1}$. Denote: $\iota_{0}^{*} \equiv \iota_{i}^{*}\left(n_{0}, \bar{\iota}_{t}\right)$ and $\iota_{1}^{*} \equiv \iota_{i}^{*}\left(n_{1}, \bar{\iota}_{t}\right)$; where $\bar{\iota}_{t} \geq 0$. Finally, suppose $\iota_{0}^{*}>\iota_{1}^{*}$. Thus, from (10), it follows that:

$$
\beta^{\prime}\left(\iota_{1}^{*}\right) \Psi\left(n_{1}, \bar{\iota}_{t}\right) \leq \beta^{\prime}\left(\iota_{0}^{*}\right) \Psi\left(n_{0}, \bar{\iota}_{t}\right) .
$$

Since, $\beta^{\prime \prime}(\iota)<0$, when $\iota_{0}^{*}>\iota_{1}^{*}, \beta^{\prime}\left(\iota_{0}^{*}\right)<\beta^{\prime}\left(\iota_{1}^{*}\right)$. As a result, $(20)$ necessarily requires that: $\Psi\left(n_{0}, \bar{\iota}_{t}\right)>\Psi\left(n_{1}, \bar{\iota}_{t}\right)$, which contradicts $\Psi_{n_{t-1}}^{\prime}>0$ for all $\bar{\iota}_{t} \geq 0$ in Lemma 3. Consequently, $n_{0}<n_{1} \Rightarrow \iota_{0}^{*} \leq \iota_{1}^{*}$.

Part 2). Take two values of $\bar{\iota} ; \bar{\iota}_{a}, \bar{\iota}_{b} \in \mathbb{R}_{+}$, such that $\bar{\iota}_{a}>\bar{\iota}_{b}$. Denote: $\iota_{a}^{*} \equiv \iota_{i}^{*}\left(n_{t-1}, \bar{\iota}_{a}\right)$ and $\iota_{b}^{*} \equiv \iota_{i}^{*}\left(n_{t-1}, \bar{\iota}_{b}\right)$; where $n_{t-1} \in[0,1]$. Finally, suppose $\iota_{a}^{*}<\iota_{b}^{*}$. Then, from (10), it follows that:

$$
\beta^{\prime}\left(\iota_{a}^{*}\right) \Psi\left(n_{t-1}, \bar{\iota}_{a}\right) \leq \beta^{\prime}\left(\iota_{b}^{*}\right) \Psi\left(n_{t-1}, \bar{\iota}_{b}\right) .
$$

In addition to that, $\beta^{\prime \prime}(\iota)<0$ implies that, if $\iota_{a}^{*}<\iota_{b}^{*}$, then $\beta^{\prime}\left(\iota_{a}^{*}\right)>\beta^{\prime}\left(\iota_{b}^{*}\right)$. As a result, (21) necessarily requires: $\Psi\left(n_{t-1}, \bar{\iota}_{a}\right)<\Psi\left(n_{t-1}, \bar{\iota}_{b}\right)$, which contradicts $\Psi_{\bar{\iota}}^{\prime}>0$ for all $n_{t} \in[0,1)$ (and $\Psi_{\bar{\iota}}^{\prime}=0$ when $n_{t}=1$ ), in Lemma 3 . Therefore, $\bar{\iota}_{a}>\bar{\iota}_{b} \Rightarrow \iota_{a}^{*} \geq \iota_{b}^{*}$.

Proof of Corollary 1. (i) Since $\Psi_{n}^{\prime}(\cdot)>0$, setting $\bar{\iota}_{t}=0$ we obtain: $\beta^{\prime}(0) \Psi\left(n_{t-1}, 0\right) \leq$ $\beta^{\prime}(0) \Psi(\bar{n}, 0)=1$, for all $n_{t-1} \leq \bar{n} . \quad \forall$ Thus, given $\beta^{\prime \prime}(\iota)<0$ and the conditions stated in (10), $\beta^{\prime}(0) \Psi\left(n_{t-1}, 0\right) \leq 1$ entails that $\iota_{i}^{*}=0$ must hold for any value of $n_{t-1} \leq \bar{n}$ when $\bar{\iota}_{t}=0$.

(ii) Since $\Psi_{n}^{\prime}(\cdot)>0$, it follows that: $\beta^{\prime}(0) \Psi\left(n_{t-1}, 0\right)>\beta^{\prime}(0) \Psi(\bar{n}, 0)=1$, for all $n_{t-1}>\bar{n}$. Therefore, given $\beta^{\prime \prime}(\iota)<0, \beta^{\prime}(0) \Psi\left(n_{t-1}, 0\right)>1$ implies that $\iota_{i}^{*}>0$ must necessarily hold for any $n_{t-1}>\bar{n}$ when $\bar{\iota}_{t}=0$, so that to comply with $(10)$. Finally, since $\Psi_{\bar{\iota}}^{\prime}(\cdot) \geq 0$,

$$
\beta^{\prime}(0) \Psi\left(n_{t-1}, \bar{\iota}_{t}\right) \geq \beta^{\prime}(0) \Psi\left(n_{t-1}, 0\right)>\beta^{\prime}(0) \Psi(\bar{n}, 0)=1, \quad \text { for all } n_{t-1}>\bar{n} \text { and } \bar{\iota}_{t}>0 .
$$

Hence, in order to comply with (10), $\iota_{i}^{*}>0$ must hold for all $n_{t-1}>\bar{n}$ and $\bar{\iota}_{t} \geq 0$.

Proof of Corollary 2. Since $\Psi_{\bar{\iota}}^{\prime}(\cdot) \geq 0$, then: $\beta^{\prime}(0) \Psi\left(n_{t-1}, \infty\right) \geq \beta^{\prime}(0) \Psi\left(n_{t-1}, \bar{\iota}_{t}\right)$, for all values of $\bar{\iota}_{t} \geq 0$ and $n_{t-1} \in[0,1]$. As a result, if $\beta^{\prime}(0) \Psi(\underline{n}, \infty)=1$, it must be the case that:

$$
\beta^{\prime}\left(\iota_{i}\right) \Psi\left(n_{t-1}, \bar{\iota}_{t}\right) \leq \beta^{\prime}(0) \Psi\left(n_{t-1}, \infty\right) \leq 1, \quad \forall n_{t-1} \leq \bar{n}, \text { and } \iota_{i}, \bar{\iota}_{t}>0 .
$$

Thus, given (10), it follows that $\iota_{i}^{*}=0$ must hold for all $n_{t-1} \leq \underline{n}$ and $\bar{\iota}_{t} \geq 0$. 
Proof of Proposition 3. (i) Take an economy in which $n_{0} \leq \bar{n}$ and focus on equilibrium $t=1$. Given Assumption 1, Corollary 1 implies there must exist a SNE in which $\iota_{1}^{*}=0$. On the other hand, Assumption 3 entails that this SNE is unique. Since $\beta(0)=0$, then (11) implies that $n_{1}=n_{0} \leq \bar{n}$. As a result, in $t=2$ conditions in the $\mathrm{R} \& \mathrm{D}$ effort game remain identical to those in $t=1$; thus, $\iota_{2}^{*}=0$ represents again the unique SNE in $t=2$. Repeating the same argument ad infinitum, it follows that: $n_{t}=n_{0} \forall t \geq 0$ and $\iota_{t}^{*}=0 \forall t>0$.

(ii) Take an economy where $n_{0}>\bar{n}$ and focus on $t=1$. Given Assumption 1, Corollary 1 implies that $\iota_{1}^{*}\left(n_{0}, 0\right)>0$. As a result, there must necessarily exist a SNE in $t=1$ in which $\iota_{1}^{*}>0$. Given Assumption 3, then this $\iota_{1}^{*}>0$ represents the unique SNE. Since $\iota_{1}^{*}>0$, from (11) it follows that $n_{1}=n_{0}+\beta\left(\iota_{1}^{*}\right)\left(1-n_{0}\right)$; hence, $n_{1}>n_{0}$. In particular, this leads to $n_{1}>n_{0}>\bar{n}$. Proposition 2 then implies that $\iota_{2}^{*}>\iota_{1}^{*}>0$. As a result of this, $n_{2}>n_{1}$. Repeating this argument ad infinitum, we can observe that: $\bar{n}<n_{0}<n_{1}<n_{2}<\ldots<n_{\infty}$. Furthermore, since $\beta\left(\iota_{t}^{*}\right)\left(1-n_{t-1}\right) \rightarrow 0$ as $n_{t} \rightarrow 1$, and because $\beta\left(\iota_{t}^{*}\right)\left(1-n_{t-1}\right)$ is bounded away from zero for any $n_{t-1} \in[0,1)$ and $\iota_{t}^{*}>0$; then it follows that $\lim _{t \rightarrow \infty} n_{t}=1$.

Proof of Lemma 5. (i) Since $\iota^{*}\left(r_{t}, w\right)$ in (16) is non-decreasing in $w$ and $\beta(\iota)$ is increasing in $\iota$, it follows that $\beta\left(\iota^{*}\left(r_{t}, w\right)\right)$ is non-decreasing in $w$. As a result, if $\Omega_{t}(w) \succeq \Omega_{t}^{\prime}(w)$, then it must be the case that $\int_{\Omega_{t}(w)} \beta\left(\iota^{*}\left(r_{t}, w\right)\right) d \Omega_{t}(w) \geq \int_{\Omega_{t}^{\prime}(w)} \beta\left(\iota^{*}\left(r_{t}, w\right)\right) d \Omega_{t}^{\prime}(w)$.

(ii) We need to prove the following: for all $w \geq 0$, and for all $n^{A}, n^{B} \in[0,1]$, such that $n^{A}>n^{B}$ : then, $\forall x \geq 0, P\left(w,[0, x] \mid n^{B}\right) \geq P\left(w,[0, x] \mid n^{A}\right)$; where $P(w,[0, x] \mid n)$ denotes the probability that when $w_{t}=w$, then $w_{t+1} \in[0, x]$, conditional on $n_{t}=n$.

Step 1: Suppose $w \in[0, \widehat{w}(r))$. Let $y\left(n_{t}, w_{t}\right) \equiv \delta\left[f\left(k_{P}^{*}\left(r_{t}\right)\right)-\left(1+r_{t}\right)\left(k_{P}^{*}\left(r_{t}\right)-w_{i, t}\right)\right]$; where the fact that $r_{t}^{*}=r\left(n_{t}\right)$ is taken into account when defining $y(\cdot)$. Notice that $\partial y / \partial n_{t}>0$ and $\partial y / \partial w_{t}=\left(1+r_{t}\right)>0$. Additionally, define the following index-function:

$$
\mathbb{I}_{y(n, w)<x}=\left\{\begin{array}{ll}
1 & \text { if } y(n, w)<x \\
0 & \text { otherwise }
\end{array} .\right.
$$

Notice that, because $\partial y / \partial n>0$, then the following two properties hold: 1) $\mathbb{I}_{y\left(n^{A}, w\right)<x}=1 \Rightarrow$ $\left.\mathbb{I}_{y\left(n^{B}, w\right)<x}=1 ; 2\right) \mathbb{I}_{y\left(n^{B}, w\right)<x}=0 \Rightarrow \mathbb{I}_{y\left(n^{A}, w\right)<x}=0$. Hence, if $\mathbb{I}_{y\left(n^{B}, w\right)<x} \neq \mathbb{I}_{y\left(n^{A}, w\right)<x}$, it must be the case that $\mathbb{I}_{y\left(n^{B}, w\right)<x}=1$ while $\mathbb{I}_{y\left(n^{A}, w\right)<x}=0$. Using (22), thus:

$$
\begin{aligned}
P\left(w,[0, x] \mid n^{B}\right)-P\left(w,[0, x] \mid n^{A}\right)= & {\left[(1-p) n^{B}+p\right] \mathbb{I}_{y\left(n^{B}, w\right)<x} } \\
& -\left[(1-p) n^{A}+p\right] \mathbb{I}_{y\left(n^{A}, w\right)<x}+(1-p)\left(n^{A}-n^{B}\right) .
\end{aligned}
$$


Hence, if $\mathbb{I}_{y\left(n^{A}, w\right)<x}=0$, the right-hand side in (23) yields a strictly positive number. Alternatively, if $\mathbb{I}_{y\left(n^{A}, w\right)<x}=1$, then the right-hand side of (23) equals zero. Therefore, $P\left(w,[0, x] \mid n^{B}\right) \geq$ $P\left(w,[0, x] \mid n^{A}\right)$ for all $w \in[0, \widehat{w}(r))$.

Step 2: Suppose $w \geq \widehat{w}(r)$. First, note that either if $\delta\left[f\left(k_{S}^{*}(w)\right)-k_{S}^{*}(w)+w\right]<x$ when $w \in$ $[\widehat{w}(r), \widetilde{w}]$, or if $\delta\left[f\left(k_{G}^{*}\right)-k_{G}^{*}(w)+w\right]<x$ when $w>\widetilde{w}$; then in both cases: $P\left(w,[0, x] \mid n^{B}\right)=$ $P\left(w,[0, x] \mid n^{A}\right)=1$. Second, when the opposite results hold, three different cases may arise: Case 1: $\delta\left(w-k_{B}^{*}\right)>x$. Then, $P\left(w,[0, x] \mid n^{B}\right)=P\left(w,[0, x] \mid n^{A}\right)=0$.

Case 2: $\delta\left[f\left(k_{B}^{*}\right)-k_{B}^{*}+w\right]>x$ and $\delta\left(w-k_{B}^{*}\right)<x$. Now, $P(w,[0, x] \mid n)=(1-p)(1-n)$; thus: $P\left(w,[0, x] \mid n^{B}\right)-P\left(w,[0, x] \mid n^{A}\right)=(1-p)\left(n^{A}-n^{B}\right)>0$.

Case 3: $\delta\left[f\left(k_{B}^{*}\right)-k_{B}^{*}+w\right]<x$ and $\delta\left(w-k_{B}^{*}\right)<x$. Now, $P(w,[0, x] \mid n)=(1-n)$; hence: $P\left(w,[0, x] \mid n^{B}\right)-P\left(w,[0, x] \mid n^{A}\right)=\left(n^{A}-n^{B}\right)>0$.

Therefore, as a result of all these four possible cases, we can deduce that: $P\left(w,[0, x] \mid n^{B}\right) \geq$ $P\left(w,[0, x] \mid n^{A}\right)$ for all $\left.w \geq \widehat{w}(r)\right)$ as well.

Proof of Proposition 4. (i) Let $\Theta$ denote the set of all feasible distribution functions $\Omega(w)$. Suppose $\Omega_{t}(w)=\Omega_{0}$. Since $n_{t-1}>\bar{n}$, then $B_{t}^{*}>0$. Furthermore, since $\Omega_{t}(w) \succeq \Omega_{0}$ for any $\Omega_{t}(w) \in \Theta$, then from Lemma $5(i)$ it follows that: $B_{t}^{*}>0$ for any $\Omega_{t}(w) \in \Theta$. Therefore, $n_{t}>n_{t-1}>\bar{n}$, implying, in turn, that $B_{t+1}^{*}>0$ for any $\Omega_{t+1}(w) \in \Theta$. Repeating the same argument ad infinitum, the claimed result obtains.

(ii) When $n_{t-1}=\bar{n}$, we have that $\beta^{\prime}(0) \Delta(\bar{r}, 0)=1$; where $\bar{r}=r(\bar{n})$. Thus, $B_{t}^{*}\left(\bar{n}, \Omega_{0}\right)=0$. Furthermore, from (16) notice that $\iota_{t}^{*}(\bar{r}, \widetilde{w})$ is the solution to:

$$
\beta^{\prime}\left(\iota_{t}^{*}(\bar{r}, \widetilde{w})\right) \Delta\left(r^{*}\left(n_{t}\right), \widetilde{w}\right)=1, \quad \text { where } n_{t}=\bar{n}+(1-\bar{n}) \beta\left(\iota_{t}^{*}(\bar{r}, \widetilde{w})\right)
$$

From Lemma 4, and the fact that $r\left(n_{t}\right) \geq \bar{r}$, it follows that $\Delta\left(r\left(n_{t}\right), \widetilde{w}\right)>\Delta(\bar{r}, 0)$. Therefore, in $(24), \iota_{t}^{*}(r(\bar{n}), \widetilde{w})>0$ must hold. Hence, there must exist $0<\bar{n}_{\widetilde{w}}<\bar{n}$, such that $\iota_{t}^{*}\left(r\left(\bar{n}_{\widetilde{w}}\right), \widetilde{w}\right)>0$ and $\bar{n}=\bar{n}_{\widetilde{w}}+\left(1-\bar{n}_{\widetilde{w}}\right) \beta\left(\iota_{t}^{*}\left(r\left(\bar{n}_{\widetilde{w}}\right), \widetilde{w}\right)\right)$; from which it follows that if $n_{t-1}>\bar{n}_{\widetilde{w}}$ when $\Omega_{t}(w)=\Omega_{\widetilde{w}}$, then $n_{t}$ will converge monotonically to $n_{\infty}=1$.

(iii) From Lemma $4(i)$, it follows that: $B_{t}^{*}\left(\bar{n}, \Omega_{t}(w)\right) \geq 0$ and $B_{t}^{*}\left(\bar{n}_{\widetilde{w}}, \Omega_{t}(w)\right) \leq B_{t}^{*}\left(\bar{n}_{\widetilde{w}}, \Omega_{\widetilde{w}}\right)$. As a result, there must exist $\bar{n}_{\Omega(w)} \in\left[\bar{n}_{\widetilde{w}}, \bar{n}\right]$, such that $B_{t}^{*}\left(\bar{n}_{\Omega(w)}, \Omega_{t}(w)\right) \geq 0$ and $\bar{n}=\bar{n}_{\Omega(w)}+(1-$ $\left.\bar{n}_{\Omega(w)}\right) B_{t}^{*}\left(\bar{n}_{\Omega(w)}, \Omega_{t}(w)\right)$; from which it follows that if $n_{t-1}>\bar{n}_{\Omega(w)}$ when $\Omega_{t}(w)$ holds, then $n_{t}$ will converge monotonically to $n_{\infty}=1$. Finally, applying Lemma $4(i)$ again $B_{t}^{*}\left(\bar{n}_{\Omega(w)}, \Omega_{t}(w)\right) \geq$ $B_{t}^{*}\left(\bar{n}_{\Omega(w)}, \Omega_{t}^{\prime}(w)\right)$ obtains, from where $\bar{n}_{\Omega(w)} \leq \bar{n}_{\Omega^{\prime}(w)}$ if $\Omega_{t}(w) \succeq \Omega_{t}^{\prime}(w)$ immediately follows. 


\section{References}

[1] Acemoglu, D., Zilibotti, F., 1997. Was Prometheus Unbound by Chance? Risk, Diversification and Growth. Journal of Political Economy 105, 709-751.

[2] Acemoglu, D., Zilibotti, F., 1999. Information Accumulation in Development. Journal of Economic Growth 4, 5-38.

[3] Aghion, P., Bolton, P., 1997. A Theory of Trickle-Down Growth and Development. Review Economic Studies 64, 151-172.

[4] Banerjee, A., Newman, A. F., 1993. Occupational Choice and the Process of Development. Journal of Political Economy 101, 274-298.

[5] Cooper, R., John, A., 1988. Coordinating Coordination Failures in Keynesian Models. Quarterly Journal of Economics 103, 651-667.

[6] Correa, R., Suarez, G., 2009. Firm Volatility and Banks: Evidence from U.S. Banking Deregulation. Finance and Economics Discussion Series 2009-46, Federal Reserve Board.

[7] Davis, S. J., Haltiwanger, J., Jarmin, R., Miranda, J., 2006. Volatility and Dispersion in Business Growth Rates: publicly traded versus privately held firms. NBER Macroeconomics Annual.

[8] De Meza, D., Webb, D., 2000. Does Credit Rationing Imply Insufficient Lending?. Journal Public Economics 78, 215-234.

[9] Feldman, M., Audretsch, D., 1999. Innovation in cities: Science-based diversity, specialization and localized competition. European Economic Review 43, 409-429.

[10] Galor, O., Zeira, J., 1993. Income Distribution and Macroeconomics. Review of Economic Studies $60,35-52$.

[11] Garcia-Vega, M., 2006. Does Technological Diversification Promote Innovation?: An empirical analysis for European firms. Research Policy 35, 230-246.

[12] Greenwood, J., Jovanovic, B., 1990. Financial Development, Growth, and the Distribution of Income. Journal of Political Economy 98, 1076-1107

[13] Goldsmith, R. W., 1969. Financial Structure and Development. New Haven: Yale Univ. Press. 
[14] Ghatak, M., Jiang, N., 2002. A Simple Model of Inequality, Occupational Choice, and Development. Journal of Development Economics 69, 205-226.

[15] Ghatak, M., Morelli, M., Sjöström, T., 2007. Entrepreneurial Talent, Occupational Choice, and Trickle Up Policies. Journal of Economic Theory 137, 27-48.

[16] Grabowski, H., 1968. The Determinants of Industrial Research and Development: A Study of the Chemical, Drug, and Petroleum Industries. Journal of Political Economy 76, 292-306.

[17] Grüner, H. P., 2003. Redistribution as a Selection Device. Journal of Economic Theory 108, 194-216.

[18] Imbs, J., Wacziarg, R., 2003. Stages of Diversification. American Economic Review 93, 63-86.

[19] Jones, B., 2008. The Knowledge Trap: human capital and development reconsidered. NBER WP 14138.

[20] Kim, S., 1989. Labor specialization and the Extent of the Market. Journal of Political Economy 97, 692-705.

[21] King, R. G., Levine, R., 1993a. Finance and Growth: Schumpeter Might be Right. Quarterly Journal Economics 108, 717-737.

[22] King, R. G., Levine, R., 1993d. Finance, Entrepreneurship, and Growth: Theory and Evidence. Journal of Monetary Economics 32, 513-542.

[23] Koren, M., Tenreyro, S., 2008. Technological Diversification. LSE, mimeo.

[24] Krugman, P., 1991. History vs. Expectations. Quarterly Journal Economics 106, 651-667.

[25] Landes, D., 1969. The Unbound Prometheus. Cambridge: Cambridge University Press.

[26] Levine, R., 1997. Financial Development and Economic Growth: Views and Agenda. Journal of Economic Literature 35, 688-726.

[27] Levine, R., Zervos, S., 1998. Stock Markets, Banks, and Economic Growth. American Economic Review 88, 537-558.

[28] Lloyd-Ellis, H., Bernhardt, D., 2000. Enterprise, Inequality and Economic Development. Review of Economic Studies 67, 147-168.

[29] Martin, A., 2009. A Model of Collateral, Investment, and Adverse Selection. Journal of Economic Theory 144, 1572-1588. 
[30] Milde, H., Riley, J.G., 1988. Signaling in Credit Markets. Quarterly Journal of Economics 103, 101-129.

[31] Miller, R. , 1984. Job Matching and Occupational Choice. Journal of Political Economy 92, 86-120.

[32] Mookherjee, D., Ray, D., 2002. Contractual Structure and Wealth Accumulation. American Economic Review 92, 818-849.

[33] Piketty, T., 1997. The Dynamics of the Wealth Distribution and the Interest Rate with Credit Rationing. Review of Economic Studies 64, 173-189.

[34] Rajan, R., Zingales, L., 1998. Financial Dependence and Growth. American Economic Review 88, $559-586$.

[35] Ramcharan, R., 2010. The Link between the Economic Structure and Financial Development. The B.E. Journal of Macroeconomics (Topics) 10, Article 12.

[36] Romer, P., 1990. Endogenous Technological Change. Journal of Political Economy 98, 71-102.

[37] Rosen, S., 1978. Substitution and Division of Labour. Economica 45, 235-250.

[38] Rothschild, M., Stiglitz, J., 1976. Equilibrium in Competitive Insurance Markets: An Essay on the Economics of Imperfect Information. Quarterly Journal of Economics 90, 629-649.

[39] Roubini, N., Sala-i-Martin, X., 1992. Financial Repression and Economic Growth. Journal of Development Economics 39, 5-30.

[40] Saint-Paul, G., 1992. Technological Choice, Financial Markets and Economic Development. European Economic Review 36, 763-781.

[41] Scherer, F., 1984. Corporative Size Diversification Innovative Activity. In: Innovation and Growth. Cambridge, MA: MIT press.

[42] Smith, A, 1776. The Wealth of Nations. Reprint. London: Methuen \& Co.

[43] Wilson, C., 1977. A Model of Insurance Markets with Incomplete Information. Journal of Economic Theory 16, 167-207.

[44] Young, A., 1928. Increasing Returns and Economic Progress. Economic Journal 38, 527-542.

[45] Yang, X., Borland, J., 1991. A Microeconomic Mechanism for Economic Growth. Journal of Political Economy 99, 460-482. 